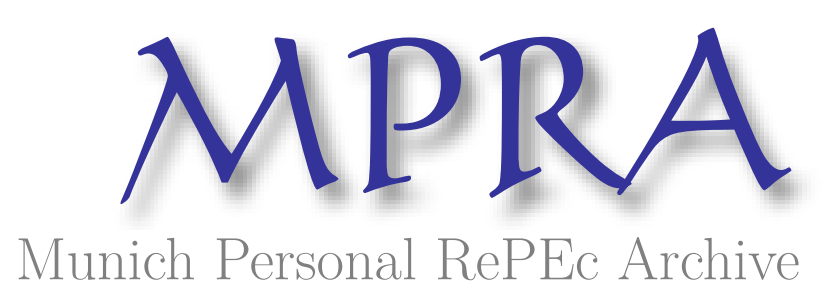

\title{
Investment decisions and sensitivity analysis: NPV-consistency of rates of return
}

Marchioni, Andrea and Magni, Carlo Alberto

Department of Economics "Marco Biagi", University of Modena and Reggio Emilia

31 January 2018

Online at https://mpra.ub.uni-muenchen.de/95266/

MPRA Paper No. 95266, posted 25 Jul 2019 07:08 UTC 


\title{
Investment decisions and sensitivity analysis: NPV-consistency of rates of return
}

\author{
Andrea Marchioni* \\ Department of Economics "Marco Biagi" \\ University of Modena and Reggio Emilia \\ andrea.marchioni@unimore.it \\ Carlo Alberto Magni ${ }^{\dagger}$ \\ Department of Economics "Marco Biagi" \\ CEFIN - Center for Research in Banking and Finance \\ University of Modena and Reggio Emilia \\ magni@unimo.it
}

\begin{abstract}
Investment decisions may be evaluated via several different metrics/criteria, which are functions of a vector of value drivers. The economic significance and the reliability of a metric depend on its compatibility with the Net Present Value (NPV). Traditionally, a metric is said to be NPV-consistent if it is coherent with NPV in signalling value creation. This paper makes use of Sensitivity Analysis (SA) for measuring coherence between rates of return and NPV. In particular, it introduces a new, stronger definition of NPV-consistency that takes into account the influence of value drivers on the metric output. A metric is strongly NPV-consistent if it signals value creation and the ranking of the value drivers in terms of impact on the output is the same as that provided by the NPV. The degree of (in)coherence is calculated with Spearman's (1904) correlation coefficient and Iman and Conover's (1987) top-down coefficient. We focus on the class of AIRRs (Magni 2010, 2013) and show that the average Return On Investment (ROI) enjoys strong NPV-consistency under several (possibly all) methods of Sensitivity Analysis.
\end{abstract}

Keywords. Finance, sensitivity analysis, investment decisions, NPV, Return On Investment, consistency, average, AIRR.

JEL codes. C4, C44, D81, M41, G31, G12, D92.

*Viale Berengario 51, 41121 Modena, Italy.

†Viale Berengario 51, 41121 Modena, Italy. Corresponding author 


\section{Introduction}

In capital budgeting many different criteria are used for evaluating a project, measuring economic efficiency, and making decisions. Net Present Value (NPV) is considered the most theoretically reliable tool, since it correctly measures shareholder value creation (Brealey and Myers 2000, Ross, Westerfield and Jordan 2011). However, in practice, many other metrics are used; in particular, relative measures of worth such as internal rate of return (IRR), profitability index (PI), modified internal rate of return (MIRR), Return On Investment (ROI), etc. Recently, a more general notion of rate of return, labeled AIRR (Average Internal Rate of Return) has been developed by Magni (2010, 2013), based on a capital-weighted mean of holding period rates. The AIRR approach consists in associating the capital amounts invested in each period with the corresponding period returns by means of a weighted arithmetic mean. Magni $(2010,2013)$ showed that any AIRR is NPV-consistent: decisions made by an investor who adopts NPV are the same as those made by an investor who adopts AIRR. Magni (2013) showed that many traditional metrics can be viewed as belonging to the class of AIRRs, including IRR, PI, MIRR. As a special case, this approach makes use of the Return On Investment (ROI) to get an average $R O I$, which is the ratio of the total project return to the total invested capital. Whatever the depreciation pattern, the average ROI exists and is unique, it has the unambiguous nature of investment rate, independent of the value drivers, and decomposes the economic value created into economic efficiency (the difference between average ROI and cost of capital) and investment scale (the sum of the committed amounts).

However, while traditional NPV-consistency is important, under uncertainty, an NPV or a rate of return are not the only factors that drive a decision. The investigation of the risk factors that mainly influence the value of the objective function is no less important.

Sensitivity analysis (SA) investigates the variation of an objective function under changes in the key inputs of a model, so aiming at identifying the most important risk factors affecting the output (and, therefore, the decision) and ranking them. There are many different SA techniques (see Pianosi et al. 2016, Borgonovo and Plischke 2016) and, given a technique, different objective functions may or may not lead to different results.

This paper positions itself in the interfaces of operational research (OR) and finance. The strict connections between operations management and finance were recognized long since (e.g., Small 1956, Weingartner 1963, Adelson 1965, Hespos and Strassman 1965, Teichroew et al. 1965a,b, Rivett 1974, Ignizio 1976) and scholarly contributions in the field have grown dramatically in the last decades (e.g., Rosenblatt and Sinuany-Stern 1989, Grubbström and Ashcroft 1991, Murthi et al. 1997, Meier et al. 2001, Gondzio and Kouwenberg 2001, Baesens et al. 2003, Steuer and Na 2003, Xu and Birge 2008, Koç et al. 2009, Fabozzi et al. 2010, Thomas 2010, Seifert et al. 2013).

The relation between OR and finance is bidirectional. On one side, finance provides a rich toolkit of theories, criteria, and methodologies which enable operational managers to better understand the impact of their decisions so as to maximize the shareholders' wealth: "In order to make decisions managers need criteria of goodness, decision tools, and an understanding of the environment in which they operate ... The main elements of 
this are that the right criterion of goodness is the maximisation of shareholder wealth and that firms operate in something close to a perfect capital market." (Ashford et al' 1988, p. 144). On the other side, operational research sets the aims and scope of financial modeling for managerial purposes: As opposed to finance theory which uses financial modeling for describing the behavior of the "average" investor and deriving the pricing process of financial assets, operational managers use financial modeling from the point of view of an individual decision maker with specific needs, constraints and preferences (Spronk and Hallerbach 1997). Further, operations research itself provides techniques and tools that may be applied to several finance problems (Board et al. 2003).

This paper is in line with the bidirectional relation between operations and finance. Specifically, it recognizes the fundamental roles of economic and financial measures of worth such as the NPV and the ROI for decision-making and, at the same time, applies an OR technique (SA) to such financial measures in order to investigate their compatibility. As such, it falls within that strand of the OR literature which makes use of various economic efficiency measures for managerial purposes, including the NPV (e.g., Yang et al. 1993, Baroum and Patterson 1996, Herroelen et al. 1997, Cigola and Peccati 2005, Borgonovo and Peccati 2006a, Wiesemann et al. 2010, Leyman and Vanhoucke 2017), the IRR (Rapp 1980, Nauss 1988, Hazen 2003, 2009, Hartman and Shafrick 2004, Dhavale and Sarkis 2018), the ROI (e.g., Danaher and Rust 1996, Myung et al. 1997, Brimberg and ReVelle 2000, Brimberg et al. 2008, Li et al. 2008, Menezes et al. 2015, Magni 2016) and the return to outlay (Kumbhakar 2011). This work is strictly linked with some recent methodological papers within this field which evaluate rationality and robustness of various efficiency measures and/or their sensitivity to changes in the key parameters. Specifically, Magni (2015) showed that the average ROI (labeled average ROA) is reliable for measuring economic efficiency in industrial applications; Mørch et al. (2017) used the average ROI as the objective function in a problem of renewal of shippings, and compared the results with those obtained from the traditional NPV maximization. Borgonovo and Peccati $(2004,2006 \mathrm{~b})$ studied the impact of the key drivers of an industrial project on NPV, IRR, and value at any time. Borgonovo et al. (2010) applied SA in a project financing transaction to assess the degree of coherence between NPV and debt service coverage ratio. Talavera et al. (2010) applied SA to the IRR of photovoltaic grid-connected systems. Percoco and Borgonovo (2012) applied SA to IRR and NPV and studied the coherence between the two metrics in terms of importance of key drivers.

We investigate the coherence of average ROI and NPV and give a new, more stringent, definition of NPV-consistency (strong coherence), according to which a metric is strongly NPV-consistent under a given SA technique if it is NPV-consistent in the traditional sense and, in addition, the ranking of the project's value drivers (in terms of influence on the output) is the same. If a metric is not NPV-consistent, the degree of inconsistency may be measured by two alternative indices: Spearman's (1904) coefficient or Iman and Conover's (1987) top-down coefficient.

We find that the average ROI is strongly NPV-consistent under many techniques, even in a strict sense (the relevances of the parameters are the same). As a result, the average ROI is a reliable measure of worth which can coherently be associated with NPV 
in investment evaluation, assessment of economic efficiency, and decision-making.

The remaining part of the paper is structured as follows. Section 2 presents the average ROI and the notion of NPV-consistency. Section 3 briefly describes some known SA methods and Section 4 introduces the notion of pairwise coherence according to which any two functions are strongly coherent if the ranking of the model parameters coincides. This section shows that, under many SA techniques, a function $f$ and an affine transformation of it share the same (ranking and) relevances of parameters, so they are strongly coherent in a strict sense. Section 5 shows that the average ROI is strongly NPV-consistent in a strict sense under many SA techniques. Some numerical examples are illustrated in section 6. Some concluding remarks end the paper. (An Appendix is devoted to some other AIRRs, including non-strongly consistent ones such as IRR, MIRR and EAIRR.)

\section{AIRR, average ROI, and NPV consistency}

Let $P$ be a project and let $\mathbf{F}=\left(F_{0}, F_{1}, \ldots, F_{p}\right) \neq \mathbf{0}$ its estimated stream of free cash flows (FCFs), where $F_{0}<0$ is the investment cost and $p$ is the lifetime of the project. Let $\tau$ be the tax rate, $R_{t}$ be the revenues, $O_{t}$ be the operating costs, and let Dep denote depreciation, $t=1,2, \ldots, p$. Then,

$$
\begin{aligned}
F_{t} & =\overbrace{\left(R_{t}-O_{t}-\operatorname{Dep}_{t}\right)(1-\tau)}^{\text {operating profit }}+\operatorname{Dep}_{t} \\
& =\left(R_{t}-O_{t}\right)(1-\tau)+\tau \cdot \operatorname{Dep}_{t} .
\end{aligned}
$$

Revenues and costs are often estimated in terms of some key inputs such as prices, quantity produced and sold, unit costs, growth rates, etc. There may be several types of costs, such as energy, material, labor, selling, general, and administrative expenses, etc. For example,

$$
F_{t}=\left(q \cdot p_{0}\left(1+g_{p}\right)^{t}-\sum_{j=1}^{s} O_{0}^{j}\left(1+g_{O^{j}}\right)^{t}\right)(1-\tau)+\tau \cdot \operatorname{Dep}_{t}
$$

where $p_{0}$ denotes the initial price, $q$ denotes the annual quantity sold, $O_{0}^{j}$ denotes the initial amount of the $j$-th item of cost, $g_{p}$ and $g_{O^{j}}$ are the growth rates, and $s$ is the number of cost items involved in the project under consideration. Let $k$ be the (assumed constant) cost of capital (COC). We assume that the COC is exogenously fixed by the decision-maker/analyst. It is well-known that net present value (NPV) measures the economic value created: NPV $=\sum_{t=0}^{p} F_{t}(1+k)^{-t}$. Therefore, the NPV decision criterion may be stated as follows:

Definition 1. (NPV criterion) A project creates value (i.e., it is worth undertaking) if and only if the project $N P V$, computed at the discount rate $k$, is positive: $N P V(k)>0$.

Let $\mathbf{C}=\left(C_{0}, C_{1}, \ldots, C_{n}\right)$ be any vector representing some notion of capital, such that $C_{0}=-F_{0}$ and $C_{n}=0$ and let $I_{t}=F_{t}+C_{t}-C_{t-1}$ be the associated return. An AIRR, denoted as $\bar{\imath}$, is defined as the ratio of the overall return $I=\sum_{t=1}^{p} I_{t}(1+k)^{-(t-1)}$ earned 
by the investor to the overall capital committed $C=\sum_{t=1}^{p} C_{t-1}(1+k)^{-(t-1)}$ :

$$
\bar{\imath}=\frac{I}{C}
$$

or, equivalently, as the weighted mean of period rates associated with the capital stream C:

$$
\bar{\imath}=\frac{\sum_{t=1}^{p} i_{t} C_{t-1} d_{t-1}}{\sum_{t=1}^{p} C_{t-1} d_{t-1}}
$$

where $d_{t}=(1+k)^{-t}$ is the discounting factor and $i_{t}=I_{t} / C_{t-1}$ is the period rate of return, $t=1,2, \ldots, p$ (see Magni 2010, 2013).

Magni $(2010,2013)$ defined a project a net investment if $C>0$ and a net financing if $C<0$. In such a way, the financial nature of any project (and its associated rate of return) can be identified as an investment project or a financing project (respectively, an investment rate or a financing rate).

Traditionally, it is widely accepted that a metric/criterion $\varphi$ is said to be NPVconsistent if and only if a decision maker adopting $\varphi$ makes the same decision suggested by the NPV criterion. We can formalize this standard notion as follows.

Definition 2. (NPV-consistency) A metric/criterion $\varphi$ is NPV-consistent if, given a cutoff rate $k$, the following statements are true:

(i) an investment project creates value if and only if $\varphi>k$

(ii) a financing project creates value if and only if $\varphi<k$.

Magni $(2010,2013)$ showed that, given a cash-flow stream $\mathbf{F}$, if $\varphi=\bar{\imath}$, then the metric is NPV-consistent, since, for any vector $\mathbf{C}$, the following product structure holds:

$$
\operatorname{NPV}(1+k)=C(\bar{\imath}-k)
$$

The above definition and eq. (4) are particularly interesting because they show that the AIRR approach enables reframing the NPV in terms of product of a capital base $C$ and an excess return $\bar{\imath}-k$. This means that the economic value created is determined by two factors: The project scale $(C)$ and the project's economic efficiency, $\bar{\imath}-k$. The same NPV can be created either by investing a large capital amount at a small rate or investing a small capital at a high rate. Furthermore, the general definition stated above enables the analyst to understand whether value is created because capital is invested at a rate of return which is higher than the COC or because capital is borrowed at a financing rate which is smaller than the COC (see also Magni 2015).

We now consider the special case of AIRR where $C_{t}=B_{t}$ is the capital which remains invested in the project at time $t: B_{t}=B_{t-1}-\operatorname{Dep}_{t}$ and $B_{0}=-F_{0}$, so that $I_{t}$ is the operating profit: $I_{t}=F_{t}+B_{t}-B_{t-1}=F_{t}-\operatorname{Dep}_{t}=\left(R_{t}-O_{t}-\operatorname{Dep}_{t}\right)(1-\tau)$. The associated period return rate is the Return on Investment (ROI):

$$
\mathrm{ROI}_{t}=\frac{\text { Operating profit }}{\text { Invested capital }}=\frac{\left(R_{t}-O_{t}-\mathrm{Dep}_{t}\right)(1-\tau)}{B_{t-1}}
$$


Thus, the AIRR becomes

$$
\bar{\imath}(B)=\frac{\text { Total Return }}{\text { Total Invested Capital }}=\frac{I}{B}
$$

where $I=\sum_{t=1}^{p}\left(\left(R_{t}-O_{t}-\operatorname{Dep}_{t}\right)(1-\tau)\right) \cdot d_{t-1}$ is the overall operating profit generated by the project and $B=\sum_{t=1}^{p} B_{t-1} d_{t-1}$ is the overall invested capital, expressing the size of the investment. As seen above, $\bar{\imath}(B)$ may be viewed as a weighted average of ROIs:

$$
\bar{\imath}(B)=\alpha_{1} \mathrm{ROI}_{1}+\alpha_{2} \mathrm{ROI}_{2}+\ldots+\alpha_{p} \mathrm{ROI}_{p}
$$

where $\alpha_{t}=B_{t-1} d_{t-1} / B$. We call $\bar{\imath}(B)$ average ROI. ${ }^{1}$ As (4) holds for any $\mathbf{C}$ (and, therefore, for $\mathbf{B}=\left(B_{0}, B_{1}, \ldots, B_{n}\right)$ as well $), \operatorname{NPV}(1+k)=B \cdot(\bar{\imath}(B)-k)$ so the average ROI is NPV-consistent (see also Magni 2015). It is also worth noting that the average ROI has the compelling property of existence and uniqueness for any project. Also, its financial nature does not depend on the value drivers nor the cost of capital: It is unambiguously determined as an investment rate, since $B_{0}=-F_{0}>0$ and $\operatorname{Dep}_{t}>0$, which implies $B>0$. This makes it a good candidate as a reliable measure of worth.

Owing to (1) and (2), the NPV is a function of several variables (the prospective revenues and costs). Practically, the analyst selects depreciation for every period, Dep $_{1}$, $\operatorname{Dep}_{2}, \ldots, \operatorname{Dep}_{p}$, then estimates the amount of sales, the initial price(s), the costs for labor, material, maintenance, energy, the growth rates, the tax rate, etc. These variables are risk factors, also known as value drivers, for they affect the FCFs. Hence, given the project COC, the project NPV is computed. For example, using (2),

$$
\mathrm{NPV}=F_{0}+\sum_{t=1}^{p} \frac{\left(q \cdot p_{0}\left(1+g_{p}\right)^{t}-\sum_{j=1}^{s} O_{0}^{j}\left(1+g_{O^{j}}\right)^{t}\right)(1-\tau)+\tau \cdot \operatorname{Dep}_{t}}{(1+k)^{t}}
$$

It is evident that the average ROI depends on these same value drivers, given that $\mathrm{ROI}_{t}$ depends on them. From (5),

$$
\mathrm{ROI}_{t}=\frac{\left(q \cdot p_{0}\left(1+g_{p}\right)^{t}-\sum_{j=1}^{s} O_{0}^{j}\left(1+g_{O^{j}}\right)^{t}-\mathrm{Dep}_{t}\right)(1-\tau)}{B_{t-1}} .
$$

Exploiting (4), one can describe the AIRR as a function of the overall capital $C$ :

$$
\bar{\imath}=\bar{\imath}(C)=k+\frac{\mathrm{NPV}}{C}(1+k) .
$$

Figure 1 graphically describes the AIRR function $\bar{\imath}(C)$ for a value-creating project; each pair $(C, \bar{\imath}(C))$ represents an NPV-consistent rate of return; among the infinitely many AIRRs, we highlight the average ROI, which is the AIRR associated with the capital stream B.

The project's aim is to check whether the coherence of average ROI and NPV, which is guaranteed in a traditional sense, remains valid if changes in value drivers are considered. The analysis of change in a model's inputs and the impact on the model output is the

\footnotetext{
${ }^{1}$ Magni (2015) used the expression average ROA for this measure.
} 


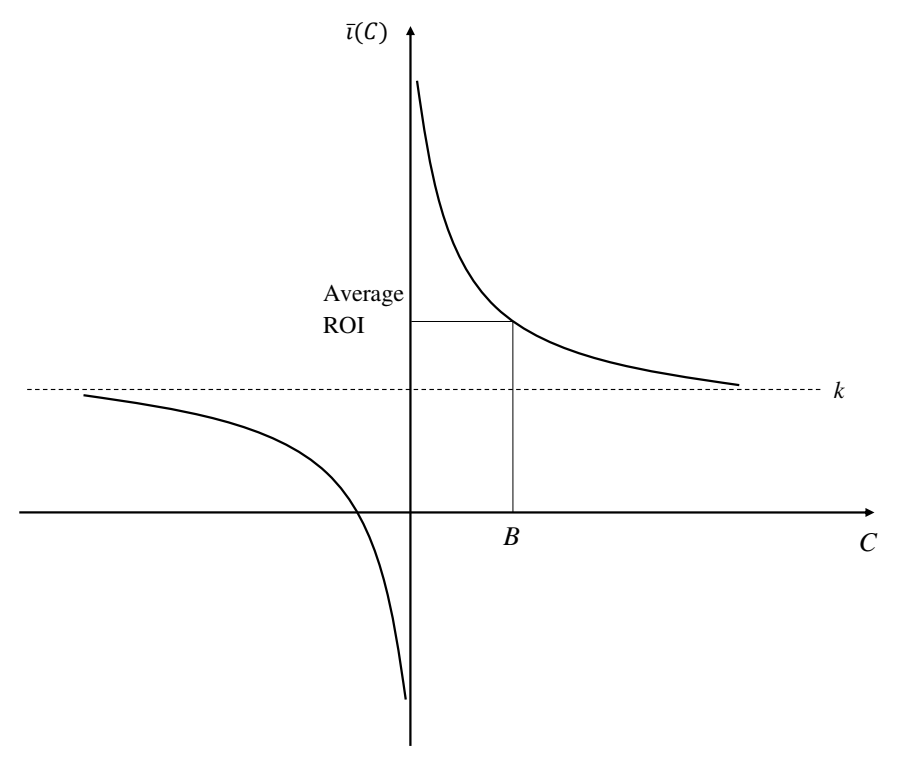

Figure 1: Graph of the AIRR function for a positive-NPV project

purpose of Sensitivity Analysis (SA). ${ }^{2}$

\section{Sensitivity analysis}

In the definition of Saltelli et al. (2004, p. 45), sensitivity analysis (SA) is the "study of how the uncertainty in the output of a model (numerical or otherwise) can be apportioned to different sources of uncertainty in the model input."

Given a model and a set of inputs (parameters), the SA investigates the relevance of parameters in terms of variability of the model output. In the literature there exist many SA techniques (see Borgonovo and Plischke 2016, Pianosi et al. 2016, for review of SA methods). A model can be described as consisting of an objective function $f$ defined on the parameter space $A$, which maps vector of inputs onto a model output $y$ :

$$
f: A \subset \mathbb{R}^{n} \rightarrow \mathbb{R}, \quad y=f(\alpha), \quad \alpha=\left(\alpha_{1}, \alpha_{2}, \ldots, \alpha_{n}\right) .
$$

The vector $\alpha=\left(\alpha_{1}, \alpha_{2}, \ldots, \alpha_{n}\right) \in A \subset \mathbb{R}^{n}$ is the vector of inputs or parameters or key drivers and $y(\alpha)$ is the output of the model. Let $\alpha^{0}=\left(\alpha_{1}^{0}, \alpha_{2}^{0}, \ldots, \alpha_{n}^{0}\right) \in A$ be the basecase, a representative value (e.g., mean value, most probable value, etc.). The relevance of a parameter $\alpha_{i}$ (also known as importance measure) quantifies the impact of $\alpha_{i}$ on the output variation. Let $R^{f}=\left(R_{1}^{f}, R_{2}^{f}, \ldots, R_{n}^{f}\right)$ be the vector of the relevances. The latter determines the ranking of the parameters in the following way. Input $\alpha_{i}$ is defined to be

\footnotetext{
${ }^{2}$ Ekern (1981) and Foster and Mitra (2003) provide conditions under which a project's NPV is greater than a second project's NPV irrespective of the COC. Assuming that the second project is the null alternative, those conditions identify those projects which are robust under changes in the COC. Those conditions hold for any AIRR as well, given that any AIRR is NPV-consistent in the traditional sense. In this paper, we measure the robustness of the project with respect to the estimates of revenues and costs and focus on their impact on NPV and rate of return.
} 
more relevant than $\alpha_{j}$ if and only if $\left|R_{i}^{f}\right|>\left|R_{j}^{f}\right|$. The parameters are equally relevant for $f$ if $\left|R_{i}^{f}\right|=\left|R_{j}^{f}\right|$. The rank of $\alpha_{i}$, denoted as $r_{i}^{f}$, depends on the importance measure: $\alpha_{i}$ has a higher rank (it has a greater impact on the output) than $\alpha_{j}$ if it has greater relevance. Let $r^{f}=\left(r_{1}^{f}, r_{2}^{f}, \ldots, r_{n}^{f}\right)$ be the vector of ranks.

The average rank is $r_{M}^{f}=\frac{\sum_{i=1}^{n} i}{n}=\frac{\frac{n \cdot(n+1)}{2}}{n}=\frac{n+1}{2}$. The high parameters (or top parameters) are those whose rank is higher than the average rank $r_{M}^{f}$; the low parameters are those parameters whose rank is smaller than $r_{M}^{f}$.

Following we briefly describe some well-known (global and local) SA techniques.

(i) Standardized regression coefficient (global SA)

Let $V$ denote variance and $\sigma$ denote standard deviation. Consider the linear regression with dependent variable $f$ and explanatory variables $\alpha_{i}, \forall i=1, \ldots, n$, estimated with OLS method: $f=\beta_{0}^{f}+\sum_{i=1}^{n} \beta_{i}^{f} \cdot \alpha_{i}+u$. The standardized regression coefficient $S R C_{i}^{f}$ measures the importance of $\alpha_{i}$ (Saltelli and Marivoet 1990, Bring 1994, Saltelli et al. 2008):

$$
S R C_{i}^{f}=\frac{\beta_{i}^{f} \cdot \sigma\left(\alpha_{i}\right)}{\sigma(f)}
$$

(ii) Sensitivity indices in variance-based decomposition methods (global SA)

In variance-based methods, the importance of a parameter is generally represented through the First Order Sensitivity Index (FOSI) and the Total Order Sensitivity Index (TOSI) (Saltelli et al. 2008). The FOSI, here denoted as $S I_{i}^{1, f}$, measures the individual effect of the parameter on the output variance:

$$
S I_{i}^{1, f}=\frac{V\left(E\left(f \mid \alpha_{i}\right)\right)}{V(f)}
$$

where $V\left(E\left(f \mid \alpha_{i}\right)\right)$ is the variance of the expectation of $f$ upon a fixed value of $\alpha_{i}{ }^{3}$ The TOSI, here denoted as $S I_{i}^{T, f}$, measures the total contribution of $\alpha_{i}$ to the output variability, i.e., it is inclusive of the interaction effects with other parameters or groups of parameters. $S I_{i}^{T, f}$ can be calculated as (Saltelli et al. 2008)

$$
S I_{i}^{T, f}=\frac{E\left(V\left(f \mid \alpha_{-i}\right)\right)}{V(f)},
$$

where $f\left|\alpha_{-i}=f\right| \alpha_{1}, \alpha_{2}, \ldots, \alpha_{i-1}, \alpha_{i+1}, \ldots, \alpha_{n}$ (see also Sobol' 1993, Sobol' 2001, Saltelli et al. 2008).

(iii) Finite Change Sensitivity Indices (global SA)

The Finite Change Sensitivity Indices (FCSIs), introduced in Borgonovo (2010a, 2010b), focus on the output change due to a finite input change; there exist two versions of FCSIs: First Order FCSI and Total Order FCSI.

The First Order FCSI of a parameter measures the individual effect of the parameter's variation on $f$; the Total Order FCSI considers the total effect of a parameter's variation on $f$, including both the individual contribution and the interactions between a parameter and the other parameters.

\footnotetext{
${ }^{3}$ It can be shown that $V\left(E\left(f \mid \alpha_{i}\right)\right)=V(f)-E\left[V\left(f \mid \alpha_{i}\right)\right]$ (see Satelli et al. 2008).
} 
Consider a change of parameters from $\alpha^{0}$ to $\alpha^{1}=\left(\alpha_{1}^{1}, \alpha_{2}^{1}, \ldots, \alpha_{n}^{1}\right) \in A$. The output variation is $\Delta f=f\left(\alpha^{1}\right)-f\left(\alpha^{0}\right)$. Let $\left(\alpha_{i}^{1}, \alpha_{(-i)}^{0}\right)=\left(\alpha_{1}^{0}, \alpha_{2}^{0}, \ldots, \alpha_{i-1}^{0}, \alpha_{i}^{1}, \alpha_{i+1}^{0}, \ldots, \alpha_{n}^{0}\right)$ be obtained by varying the parameter $\alpha_{i}$ to the new value $\alpha_{i}^{1}$, while the remaining $n-1$ parameters are fixed at $\alpha^{0}$. The individual effect of $\alpha_{i}$ on $\Delta f$ is $\Delta_{i} f=f\left(\alpha_{i}^{1}, \alpha_{(-i)}^{0}\right)-f\left(\alpha^{0}\right)$ and the First Order FCSI of $\alpha_{i}$, denoted as $\Phi_{i}^{1, f}$, is (Borgonovo 2010a):

$$
\Phi_{i}^{1, f}=\frac{\Delta_{i} f}{\Delta f}
$$

$\Delta f$ is equal to the sum of individual effects and interactions between parameters and groups of parameters. The total effect of the parameter $\alpha_{i}$, denoted as $\Delta_{i}^{T} f$, is the sum of the individual effect of $\alpha_{i}$ and of the interactions that involve $\alpha_{i}$. Borgonovo (2010a, Proposition 1) showed that $\Delta_{i}^{T} f$ can be obtained as $\Delta_{i}^{T} f=f\left(\alpha^{1}\right)-f\left(\alpha_{i}^{0}, \alpha_{(-i)}^{1}\right)$ for all $i=1,2, \ldots, n$, where $\left(\alpha_{i}^{0}, \alpha_{(-i)}^{1}\right)$ is the point with all the parameters equal to the new value $\alpha^{1}$, except the parameter $\alpha_{i}$, which is equal to $\alpha_{i}^{0}$. The Total Order FCSI of the parameter $\alpha_{i}$, denoted as $\Phi_{i}^{T, f}$, is (Borgonovo 2010a):

$$
\Phi_{i}^{T, f}=\frac{\Delta_{i}^{T} f}{\Delta f}=\frac{f\left(\alpha^{1}\right)-f\left(\alpha_{i}^{0}, \alpha_{(-i)}^{1}\right)}{\Delta f} .
$$

(iv) Helton's index (local SA)

Helton (1993) proposed a variance decomposition of $f$ based on Taylor approximation. He assumed parameters are not correlated, so the variance of $f$ can be approximated by

$$
\hat{V}(f)=\sum_{i=1}^{n}\left[f_{\alpha_{i}}^{\prime}\left(\alpha^{0}\right)\right]^{2} \cdot V\left(\alpha_{i}\right) .
$$

The impact of input $\alpha_{i}$ on $V(f)$ can be measured by

$$
H_{i}^{f}\left(\alpha^{0}\right)=\frac{\left[f_{\alpha_{i}}^{\prime}\left(\alpha^{0}\right)\right]^{2} \cdot V\left(\alpha_{i}\right)}{\hat{V}(f)} .
$$

\section{(v) Normalized Partial Derivatives (local SA)}

Helton (1993) also proposed the adoption of normalized partial derivatives as sensitivity measures. He defined two versions of normalized partial derivatives (NPDs):

$$
\begin{aligned}
& N P D 1_{i}^{f}\left(\alpha^{0}\right)=f_{\alpha_{i}}^{\prime}\left(\alpha^{0}\right) \cdot \frac{\alpha_{i}^{0}}{f\left(\alpha^{0}\right)}, \\
& N P D 2_{i}^{f}\left(\alpha^{0}\right)=f_{\alpha_{i}}^{\prime}\left(\alpha^{0}\right) \cdot \frac{\sigma\left(\alpha_{i}\right)}{\hat{\sigma}(f)},
\end{aligned}
$$

where $\hat{\sigma}(f)$ is the square root of $\hat{V}(f)$ defined in (16). $N P D 1_{i}^{f}\left(\alpha^{0}\right)$ measures the elasticity of $f$ with respect to $\alpha_{i}$ in $\alpha^{0}$ assuming that the relative change in $\alpha_{i}$ is fixed for $i=$ $1,2, \ldots, n$ (Helton 1993, p. 329). $\left|N P D 2_{i}^{f}\left(\alpha^{0}\right)\right|$ is the square root of (17).

(vi) Differential Importance Measure (local SA)

The total variation $f\left(\alpha^{0}+\mathrm{d} \alpha\right)-f\left(\alpha^{0}\right)$ of a differentiable function $f$ due to a local change $\mathrm{d} \alpha$ can be approximated by the total differential $\mathrm{d} f=\sum_{i=1}^{n} f_{\alpha_{i}}^{\prime}\left(\alpha^{0}\right) \cdot \mathrm{d} \alpha_{i}$. The Differential 
Importance Measure (DIM) of parameter $\alpha_{i}$ is the ratio of the partial differential of $f$ with respect to $\alpha_{i}$ to the total differential of $f$ (Borgonovo and Apostolakis 2001, Borgonovo and Peccati 2004):

$$
D I M_{i}^{f}\left(\alpha^{0}, \mathrm{~d} \alpha\right)=\frac{\mathrm{d} f_{a_{i}}}{\mathrm{~d} f}=\frac{f_{\alpha_{i}}^{\prime}\left(\alpha^{0}\right) \cdot \mathrm{d} \alpha_{i}}{\sum_{j=1}^{n} f_{\alpha_{j}}^{\prime}\left(\alpha^{0}\right) \cdot \mathrm{d} \alpha_{j}} .
$$

The DIM of a parameter represents the percentage of the function's variation due to the variation of that parameter (Borgonovo and Apostolakis 2001, Borgonovo and Peccati 2004).

\section{Coherence between objective functions}

Risk management problems are often characterized by the definition of more than one objective function (Borgonovo and Peccati 2006b, Borgonovo, Gatti and Peccati 2010). For a given technique, the analysis can be applied using different objective functions. A relevant aspect is the evaluation of the coherence (or compatibility) between the results of the sensitivity analysis for different functions.

We consider the objective functions $f, g: A \rightarrow \mathbb{R}$. The vector of importance measures are respectively $R^{f}=\left(R_{1}^{f}, R_{2}^{f}, \ldots, R_{n}^{f}\right)$ and $R^{g}=\left(R_{1}^{g}, R_{2}^{g}, \ldots, R_{n}^{g}\right)$; the ranking vectors are $r^{f}=\left(r_{1}^{f}, r_{2}^{f}, \ldots, r_{n}^{f}\right)$ and $r^{g}=\left(r_{1}^{g}, r_{2}^{g}, \ldots, r_{n}^{g}\right)$.

Definition 3. (Coherence) Given a technique of $S A$ and two objective functions $f$ and $g$, they are coherent if the ranking vectors coincide: $r^{f}=r^{g}$. If, in addition, the vectors of the relevances coincide, $R^{f}=R^{g}$, they are strictly coherent.

If two functions $f$ and $g$ are not coherent, the degree of incoherence can be alternatively measured through Spearman's rank correlation coefficient (Spearman 1904) or top-down correlation coefficient (Iman and Conover 1987).

Spearman's rank correlation coefficient (henceforth, Spearman's coefficient) between two stochastic variables is the correlation coefficient between the ranks of the stochastic variables (Spearman 1904). In SA, Spearman's coefficient between two objective functions $f$ and $g$, denoted as $\rho_{f, g}$, is the correlation coefficient of the ranking vectors $r^{f}$ and $r^{g}$ :

$$
\rho_{f, g}=\frac{\operatorname{Cov}\left(r^{f}, r^{g}\right)}{\sigma\left(r^{f}\right) \cdot \sigma\left(r^{g}\right)}=\frac{\sum_{i=1}^{n}\left(r_{i}^{f}-r_{M}^{f}\right) \cdot\left(r_{i}^{g}-r_{M}^{g}\right)}{\sqrt{\sum_{i=1}^{n}\left(r_{i}^{f}-r_{M}^{f}\right)^{2}} \cdot \sqrt{\sum_{i=1}^{n}\left(r_{i}^{g}-r_{M}^{g}\right)^{2}}},
$$

where, as seen, $r_{M}^{f}=r_{M}^{g}=\frac{n+1}{2}$. The coefficient $\rho_{f, g}$ attributes the same weight to top and low parameters and lies in the interval $[-1,1]$. The coefficient $\rho_{f, g}$ is equal to 1 if and only if $f$ and $g$ are coherent according to Definition 3. Therefore, a value of $\rho_{f, g}$ smaller than 1 signals incoherence between $f$ and $g$ : The smaller the value of $\rho_{f, g}$, the higher the degree of incoherence. The difference $1-\rho_{f, g}$ can be taken as representative of the degree of incoherence.

Iman and Conover (1987) introduced the top-down correlation coefficient, a compatibility measure that attributes a higher weight to top parameters than to low parameters. 
This measure is based on Savage Score (Savage 1956). The Savage score of parameter $\alpha_{i}$ is $S_{i}^{f}=\sum_{h=r_{i}^{f}}^{n} \frac{1}{h}$. The vector of Savage scores is $S^{f}=\left(S_{1}^{f}, S_{2}^{f}, \ldots, S_{n}^{f}\right)$. ${ }^{4}$ The average Savage score is $S_{M}^{f}=\frac{\sum_{i=1}^{n} S_{i}^{f}}{n}=1$.

The top-down correlation coefficient between the objective functions $f$ and $g$, denoted as $\rho_{S^{f}, S^{g}}$, is the correlation coefficient between the Savage scores' vectors $S^{f}$ and $S^{g}$ (Iman and Conover 1987):

$$
\rho_{S^{f}, S^{g}}=\frac{\operatorname{Cov}\left(S^{f}, S^{g}\right)}{\sigma\left(S^{f}\right) \cdot \sigma\left(S^{g}\right)}=\frac{\sum_{i=1}^{n}\left(S_{i}^{f}-S_{M}^{f}\right) \cdot\left(S_{i}^{g}-S_{M}^{g}\right)}{\sqrt{\sum_{i=1}^{n}\left(S_{i}^{f}-S_{M}^{f}\right)^{2}} \cdot \sqrt{\sum_{i=1}^{n}\left(S_{i}^{g}-S_{M}^{g}\right)^{2}}},
$$

where $S_{M}^{f}=S_{M}^{g}=1$. The coefficient $\rho_{S^{f}, S^{g}}$ measures the compatibility between the parameters' ranking of $f$ and $g$ : The accordance between top parameters has a remarkable influence on $\rho_{S^{f}, S^{g}}$, while the discordance between low parameters has a weak influence on $\rho_{S^{f}, S^{g}}$ (Iman and Conover 1987).

If the aim of the analysis is factor prioritization (i.e., identification of the most relevant parameters), the top-down coefficient should be preferred to Spearman's coefficient.

The maximum value of $\rho_{S^{f}, S^{g}}$ is equal to 1 . In case $f$ and $g$ have no ties (i.e., no relevance is equal), the minimum value is -1 for $n=2$, it increases as $n$ increases, and it tends to -0.645 as $n$ tends to infinity (Iman and Conover 1987).

$\rho_{S^{f}, S^{g}}$ is equal to 1 if and only if $f$ and $g$ are coherent. Therefore, a value of $\rho_{S^{f}, S^{g}}$ smaller than 1 signals incompatibility between $f$ and $g$. The smaller the value of $\rho_{S^{f}, S^{g}}$, the higher the incoherence level. The degree of incoherence of $f$ and $g$ can then be measured by $1-\rho_{S^{f}, S^{g}}$.

Borgonovo et al. (2014) showed that an objective function $f$ and a monotonic transformation $g$ of it generate the same ranking of the parameters under several techniques. This means that they are coherent according to Definition 3.

We now show that, if $g$ is an affine transformation of $f$, that is, $g(\alpha)=l \cdot f(\alpha)+q$ for all $\alpha \in A$, then $f$ and $g$ are strictly coherent under several techniques.

Proposition 1. A function and an affine transformation of it are strictly coherent under the following techniques:

(i) Standardized regression coefficient

(ii) Sensitivity Indices in variance-based decomposition methods

(iii) Finite Change Sensitivity Indices

(iv) Helton's index

(v) Normalized Partial Derivative $\left(N P D 2_{i}^{f}\right)$

(vi) Differential Importance Measure.

Proof. By hypothesis, $g(\alpha)=l \cdot f(\alpha)+q$. Therefore,

\footnotetext{
${ }^{4}$ For example, if $n=5$ and $r^{f}=(1,2,3,4,5)$, then $S^{f}=(2.28 \overline{3}, 1.28 \overline{3}, 0.78 \overline{3}, 0.45,0.2)$.
} 
(i) $g=l \cdot\left(\beta_{0}^{f}+\sum_{i=1}^{n} \beta_{i}^{f} \cdot \alpha_{i}+u\right)+q=\left(l \cdot \beta_{0}^{f}+q\right)+\sum_{i=1}^{n}\left(l \cdot \beta_{i}^{f}\right) \cdot \alpha_{i}+l \cdot u$, whence

$$
\begin{aligned}
& \beta_{0}^{g}=l \cdot \beta_{0}^{f}+q, \\
& \beta_{i}^{g}=l \cdot \beta_{i}^{f}
\end{aligned}
$$

so that

$$
S R C_{i}^{g}=\frac{\beta_{i}^{g} \cdot \sigma\left(\alpha_{i}\right)}{\sigma(g)}=\frac{l \cdot \beta_{i}^{f} \cdot \sigma\left(\alpha_{i}\right)}{l \cdot \sigma(f)}=S R C_{i}^{f} .
$$

(ii) Denoting as $f \mid \alpha_{i}$ (and $g \mid \alpha_{i}$ ) the function $f$ (and $g$ ) conditional to a specific value of $\alpha_{i}, g\left|\alpha_{i}=(l \cdot f+q)\right| \alpha_{i}=(l \cdot f)\left|\alpha_{i}+q=l \cdot f\right| \alpha_{i}+q$. Therefore,

$$
S I_{i}^{1, g}=\frac{V\left(E\left(g \mid \alpha_{i}\right)\right)}{V(g)}=\frac{V\left(E\left(l \cdot f \mid \alpha_{i}+q\right)\right)}{V(l \cdot f+q)}=\frac{l^{2} \cdot V\left(E\left(f \mid \alpha_{i}\right)\right)}{l^{2} \cdot V(f)}=S I_{i}^{1, f} .
$$

Analogously, $g\left|\alpha_{-i}=(l \cdot f+q)\right| \alpha_{-i}=l \cdot f \mid \alpha_{-i}+q$. Hence,

$$
S I_{i}^{T, g}=\frac{E\left(V\left(g \mid \alpha_{-i}\right)\right)}{V(g)}=\frac{E\left(V\left(l \cdot f \mid \alpha_{-i}+q\right)\right)}{V(l \cdot f+q)}=\frac{l^{2} \cdot E\left(V\left(f \mid \alpha_{-i}\right)\right)}{l^{2} \cdot V(f)}=S I_{i}^{T, f} .
$$

(iii) Since $\Delta g=g\left(\alpha^{1}\right)-g\left(\alpha^{0}\right)=l \cdot f\left(\alpha^{1}\right)+q-l \cdot f\left(\alpha^{0}\right)-q=l \cdot\left(f\left(\alpha^{1}\right)-f\left(\alpha_{0}\right)\right)=l \cdot \Delta f$, and

$$
\begin{aligned}
\Delta_{i} g & =g\left(\alpha_{i}^{1}, \alpha_{(-i)}^{0}\right)-g\left(\alpha^{0}\right)=l \cdot f\left(\alpha_{i}^{1}, \alpha_{(-i)}^{0}\right)+q-l \cdot f\left(\alpha^{0}\right)-q \\
& =l \cdot\left(f\left(\alpha_{i}^{1}, \alpha_{(-i)}^{0}\right)-f\left(\alpha^{0}\right)\right)=l \cdot \Delta_{i} f
\end{aligned}
$$

then

$$
\Phi_{i}^{1, g}=\frac{\Delta_{i} g}{\Delta g}=\frac{l \cdot \Delta_{i} f}{l \cdot \Delta f}=\frac{\Delta_{i} f}{\Delta f}=\Phi_{i}^{1, f} .
$$

As for the Total Indices,

$$
\begin{aligned}
\Delta_{i}^{T} g & =g\left(\alpha^{1}\right)-g\left(\alpha_{i}^{0}, \alpha_{(-i)}^{1}\right)=l \cdot f\left(\alpha^{1}\right)+q-l \cdot f\left(\alpha_{i}^{0}, \alpha_{(-i)}^{1}\right)-q \\
& =l \cdot\left(f\left(\alpha^{1}\right)-f\left(\alpha_{i}^{0}, \alpha_{(-i)}^{1}\right)\right)=l \cdot \Delta_{i}^{T} f
\end{aligned}
$$

so that

$$
\Phi_{i}^{T, g}=\frac{\Delta_{i}^{T} g}{\Delta g}=\frac{l \cdot \Delta_{i}^{T} f}{l \cdot \Delta f}=\frac{\Delta_{i}^{T} f}{\Delta f}=\Phi_{i}^{T, f}
$$

(iv) From (16),

$$
\begin{aligned}
\hat{V}(g) & =\sum_{i=1}^{n}\left[g_{\alpha_{i}}^{\prime}\left(\alpha^{0}\right)\right]^{2} \cdot V\left(\alpha_{i}\right) \\
& =\sum_{i=1}^{n}\left[l \cdot f_{\alpha_{i}}^{\prime}\left(\alpha^{0}\right)\right]^{2} \cdot V\left(\alpha_{i}\right)=l^{2} \cdot \sum_{i=1}^{n}\left[f_{\alpha_{i}}^{\prime}\left(\alpha^{0}\right)\right]^{2} \cdot V\left(\alpha_{i}\right)=l^{2} \cdot \hat{V}(f) .
\end{aligned}
$$

Hence,

$$
H_{i}^{g}\left(\alpha^{0}\right)=\frac{\left[g_{\alpha_{i}}^{\prime}\left(\alpha^{0}\right)\right]^{2} \cdot V\left(\alpha_{i}\right)}{\hat{V}(g)}=\frac{l^{2} \cdot\left[f_{\alpha_{i}}^{\prime}\left(\alpha^{0}\right)\right]^{2} \cdot V\left(\alpha_{i}\right)}{l^{2} \cdot \hat{V}(f)}=H_{i}^{f}\left(\alpha^{0}\right) .
$$


(v) Straightforward, since $\left|N P D 2_{i}^{f}\right|$ is the square root of $H_{i}^{f}\left(\alpha^{0}\right){ }^{5}$

(vi) From (20),

$$
\begin{aligned}
D I M_{i}^{g}\left(\alpha^{0}, \mathrm{~d} \alpha\right) & =\frac{g_{\alpha_{i}}^{\prime}\left(\alpha^{0}\right) \cdot \mathrm{d} \alpha_{i}}{\sum_{j=1}^{n} g_{\alpha_{j}}^{\prime}\left(\alpha^{0}\right) \cdot \mathrm{d} \alpha_{j}}=\frac{l \cdot f_{\alpha_{i}}^{\prime}\left(\alpha^{0}\right) \cdot \mathrm{d} \alpha_{i}}{\sum_{j=1}^{n} l \cdot f_{\alpha_{j}}^{\prime}\left(\alpha^{0}\right) \cdot \mathrm{d} \alpha_{j}}=\frac{f_{\alpha_{i}}^{\prime}\left(\alpha^{0}\right) \cdot \mathrm{d} \alpha_{i}}{\sum_{j=1}^{n} f_{\alpha_{j}}^{\prime}\left(\alpha^{0}\right) \cdot \mathrm{d} \alpha_{j}} \\
& =D I M_{i}^{f}\left(\alpha^{0}, \mathrm{~d} \alpha\right) .
\end{aligned}
$$

(This result is independent of the structure of $\mathrm{d} \alpha$.)

Remark 1. While we have proved that, for several SA techniques, a function and its affine transformation are coherent (even in a strict sense), it is intuitive to inductively believe that a function and its affine transformation share an absolute coherence, in that they are coherent for every existing SA technique. We leave the proof of this more general statement for future research.

\section{Coherence between return rates and NPV}

The investment risk can be defined as "the potential variability of financial outcomes" (White et al. 1997). The future outcomes of an investment are stochastic and the investor has limited information. Referring to NPV and IRR, Joy and Bradley (1973, p. 1255) wrote: "It has often been suggested that capital budgeting theory has over-emphasized the development of such techniques with little regard for the typically poor data used in project evaluation and the effect that errors in capital budgeting inputs have on project profitability." The practice of valuation criteria should be corroborated by a careful investment risk analysis.

Given an investment model based on a set of value drivers, SA allows the evaluator to identify the most relevant parameters in terms of variation of the value. The most relevant parameters are the risk factors that mainly influence the investment. After SA has been performed, the investment risk can be reduced through information insights on the main risk factors identified by the analysis; the collection of extra information on these parameters allows more precise estimates and a remarkable uncertainty reduction (Borgonovo and Peccati 2006b). Furthermore, the potential investor is able to appreciate the convenience of possible hedging strategies.

As the NPV is the main decision criterion in capital budgeting theory, the analysis of the parameters' relevance on NPV variability is fundamental. Any relative measure of worth should be consistent with NPV not only in terms of classical consistency but also in terms of output variability with respect to changes in the inputs.

${ }^{5}$ It is worth noting that $f$ and $g$ are coherent but not strictly coherent under $N P D 1_{i}^{f}$ technique:

$$
N P D 1_{i}^{g}\left(\alpha^{0}\right)=g_{\alpha_{i}}^{\prime}\left(\alpha^{0}\right) \cdot \frac{\alpha_{i}^{0}}{g\left(\alpha^{0}\right)}=l \cdot f_{\alpha_{i}}^{\prime}\left(\alpha^{0}\right) \cdot \frac{\alpha_{i}^{0}}{g\left(\alpha^{0}\right)} \cdot \frac{f\left(\alpha^{0}\right)}{f\left(\alpha^{0}\right)}=l \cdot \frac{f\left(\alpha^{0}\right)}{g\left(\alpha^{0}\right)} \cdot N P D 1_{i}^{f}\left(\alpha^{0}\right)
$$

so that $\left|N P D 1_{i}^{f}\right|>\left|N P D 1_{j}^{f}\right|$ implies $\left|N P D 1_{i}^{g}\right|>\left|N P D 1_{j}^{g}\right|$. Therefore, the parameters' ranking in $f$ and $g$ is equal: $r^{f}=r^{g}$. 
Definition 4. (Strong NPV-consistency) Given an analysis technique T, a metric $\varphi$ (and its associated decision criterion) is strongly NPV-consistent (or coherent with NPV) under $T$ if it fulfills Definition 2 and $N P V$ and $\varphi$ are coherent functions. The metric $\varphi$ is strictly $N P V$-consistent if the coherence is strict.

If a metric/criterion possesses strong NPV-consistency, the investor can equivalently adopt NPV or such criterion for measuring value creation under uncertainty. In case a metric is not strongly NPV-consistent, the degree of incompatibility can be measured through Spearman's coefficient or through top-down coefficient, as seen in section 4 .

We now show that the average ROI possesses strong NPV-consistency. To this end, we maintain the symbol $\alpha=\left(\alpha_{1}, \ldots, \alpha_{n}\right)$ as the vector of the project's value drivers and $\alpha^{0}$ is the base value. We assume that the initial invested capital (or borrowed amount) is exogenously given, as well as the COC (and $p$ ). The economic profitability of $P$ depends on the realization of the value drivers, which affect the FCFs, as seen in section $2: F_{t}=F_{t}(\alpha)$, $t=1,2, \ldots p$. We now let $f(\alpha)=\operatorname{NPV}(\alpha)=-B_{0}+\sum_{t=1}^{p} F_{t}(\alpha)(1+k)^{-t}$ and $g(\alpha)$ denotes the average ROI.

Proposition 2. For any fixed $k, p$ and $\mathbf{D e p}=\left(\right.$ Dep $_{1}, \ldots$, Dep $\left.p\right),{ }^{6}$ average ROI and NPV are strongly consistent in a strict sense under the following techniques:

(i) Standardized regression coefficient

(ii) Sensitivity Indices in variance-based decomposition methods

(iii) Finite Change Sensitivity Indices

(iv) Helton's index

(v) Normalized Partial Derivative $\left(N P D 2_{i}^{f}\right)$

(vi) Differential Importance Measure.

Proof. The depreciation charge, Dep $_{t}$, does not depend on the value drivers; therefore, $B$ does not depend on $\alpha$ and, using (9), one can write $g(\alpha)=q+l \cdot \operatorname{NPV}(\alpha)$ where $q=k$ and $l=(1+k) / B$. The thesis follows from Proposition $1 .{ }^{7}$

The above proposition guarantees that the value drivers' effect on the variability of $\bar{\imath}(B)$ and NPV is the same, not only in terms of ranks $\left(r^{\mathrm{npv}}=r^{\overline{(}(B)}\right)$ but also in terms of relevances $\left(R^{\mathrm{npv}}=R^{\bar{\imath}(B)}\right)$. Therefore, $\rho_{\bar{\imath}(B), \mathrm{npv}}=\rho_{S^{\bar{\imath}(B)}, S^{\mathrm{npv}}}=1$. This means that an investor can equivalently employ average ROI or NPV to analyze an investment under uncertainty.

\section{$6 \quad$ Worked examples}

In the previous sections we have shown that, given a depreciation plan, the average ROI is strongly consistent with NPV. The aim of this section is to discuss two models. The first analyzes an example with straight-line depreciation. The second one is a real-life application, illustrated in Hartman (2007, p. 344) and is based on declining balance depreciation. We will accomplish a SA by focusing on two techniques: FCSI and DIM.

${ }^{6}$ Obviously, to fix Dep is equivalent to fixing B.

${ }^{7}$ Evidently, $\bar{\imath}(B)$ is strongly NPV-consistent under $N P D 1_{i}^{f}$ as well but not in a strict sense. 


\subsection{Straight-line depreciation}

We discuss a simple model, consisting of a firm facing the opportunity of investing in a 4-period project whose estimated revenues and operating costs are $R_{t}$ and $O_{t}$. We assume that the tax rate is zero, $\tau=0$ (it is not a risk factor). This implies, from (1), $F_{t}=R_{t}-O_{t}$. The project's value drivers are then $\alpha_{i}=R_{i}$ for $i=1,2,3,4$ and $\alpha_{i}=O_{i-4}$ for $i=5,6,7,8$. Hence, the value driver's vector is $\alpha=\left\{R_{1}, R_{2}, R_{3}, R_{4}, O_{1}, O_{2}, O_{3}, O_{4}\right\}$. $\mathrm{NPV}$ is computed as:

$$
\mathrm{NPV}(\alpha)=-B_{0}+\frac{R_{1}-O_{1}}{1+k}+\frac{R_{2}-O_{2}}{(1+k)^{2}}+\frac{R_{3}-O_{3}}{(1+k)^{3}}+\frac{R_{4}-O_{4}}{(1+k)^{4}}
$$

We assume that straight-line (SL) depreciation is employed, which implies that the invested capital depreciates linearly with time: $\operatorname{Dep}_{t}=\gamma B_{0}$ where $\gamma=1 / p$. This means $B_{t}=B_{0}(1-\gamma t)$ and, in turn, $B=B_{0} \cdot \sum_{t=1}^{p}\left(1-\frac{t-1}{p}\right)(1+k)^{-(t-1)}$. This implies $\mathrm{ROI}_{t}=\left(R_{t}-O_{t}-\gamma B_{0}\right) /\left(B_{0}(1-\gamma(t-1))\right)$. The average ROI can be computed as a weighted average of the ROIs or as the ratio of overall profit to overall capital, $B$. Equivalently, using NPV, one can compute it as the value obtained by the AIRR function at $C=B$. Specifically, $\bar{\imath}(B)=k+\operatorname{NPV}(1+k) / B$.

Example 1. Assume $B_{0}=750$ and $k=10 \%$. Table 1 describes the base value

$$
\alpha^{0}=\left(R_{1}^{0}, R_{2}^{0}, R_{3}^{0}, R_{4}^{0}, O_{1}^{0}, O_{2}^{0}, O_{3}^{0}, O_{4}^{0}\right)
$$

and reports the corresponding Free Cash Flows and valuation metrics. The NPV is $157.37=-750+380 / 1.1+270 /(1.1)^{2}+360 /(1.1)^{3}+100 /(1.1)^{4}$. Considering that depreciation charge is $750 / 4=187.5$, the vector of capitals associated with the average $\mathrm{ROI}$ is $\mathbf{B}=$ $(750,562.5,375,187.5,0)$ and $B=1712.15=750+562.5 / 1.1+375 /(1.1)^{2}+187.5 /(1.1)^{3}$. Therefore, the average ROI is equal to $\bar{\imath}(B)=10 \%+157.37 / 1712.15 \cdot 1.1=20.11 \%$.

Table 1: Investment evaluated in $\alpha^{0}$

\begin{tabular}{lccccc}
\hline & 0 & 1 & 2 & 3 & 4 \\
\hline$R_{t}^{0}$ & & 580 & 570 & 560 & 400 \\
$O_{t}^{0}$ & & 200 & 300 & 200 & 300 \\
$F_{t}$ & -750 & 380 & 270 & 360 & 100 \\
\hline Valuation & & & & & \\
\hline NPV & 157.37 & & & & \\
$\bar{\imath}(B)$ & $20.11 \%$ & & & & \\
\hline
\end{tabular}

Let $\alpha^{1}$ be the vector of new values of revenues and costs (see Table 2), with the corresponding new values of $F_{t}$, NPV, and $\bar{\imath}(B)$. In $\alpha^{1}$, NPV is $442.92, \bar{\imath}(B)$ is $38.46 \%$. The observed variations are: $\Delta \mathrm{NPV}=285.55=442.92-157.37 ; \Delta \bar{\imath}(B)=18.35 \%=$ $38.46 \%-20.11 \%$. Table 3 shows the First Order FCSIs $\left(\Phi_{i}^{1, f}\right)$, the ranks $\left(r_{i}^{f}\right)$, and the Savage scores of parameters $\left(S_{i}^{f}\right)$ for NPV and $\bar{\imath}(B)$. The First Order FCSIs are equal: $\Phi_{i}^{1, \mathrm{npv}}=\Phi_{i}^{1, \bar{\imath}(B)}$. Hence, $\bar{\imath}(B)$ and NPV are strongly coherent in a strict sense and the degree of coherence is maximum: $\rho_{\bar{\imath}(B), \mathrm{npv}}=\rho_{S^{\bar{\imath}}(B), S^{\mathrm{npv}}}=1$. (Note that, in this case, Total Order FCSIs and First Order FCSIs coincide, because the value drivers do not interact one another.) 
Table 2: Investment evaluated in $\alpha^{1}$

\begin{tabular}{lccccc}
\hline & 0 & 1 & 2 & 3 & \multicolumn{1}{c}{4} \\
\hline$R_{t}^{1}$ & & 800 & 810 & 780 & 630 \\
$O_{t}^{1}$ & & 350 & 250 & 380 & 600 \\
$F_{t}$ & -750 & 450 & 560 & 400 & 30 \\
\hline Valuation & & & & & \\
\hline NPV & 442.92 & & & & \\
$\bar{\imath}(B)$ & $38.46 \%$ & & & & \\
\hline
\end{tabular}

Table 3: Finite Change Sensitivity Indices

\begin{tabular}{|c|c|c|c|c|c|c|c|}
\hline \multirow[b]{2}{*}{ Parameter } & \multicolumn{3}{|c|}{ NPV } & \multicolumn{4}{|c|}{ Average ROI } \\
\hline & $\Phi_{i}^{T, \mathrm{npv}}=\Phi_{i}^{1, \mathrm{npv}}$ & $r_{i}^{\mathrm{npv}}$ & $S_{i}^{\text {npv }}$ & $\Phi_{i}^{T, \bar{\imath}(B)}$ & $=\Phi_{i}^{1, \bar{\imath}(B)}$ & $r_{i}^{\bar{\imath}(B)}$ & $S_{i}^{\overline{\bar{c}(B)}}$ \\
\hline$R_{1}$ & $70.04 \%$ & 2 & 1.718 & & $70.04 \%$ & 2 & 1.718 \\
\hline$R_{2}$ & $69.46 \%$ & 3 & 1.218 & & $69.46 \%$ & 3 & 1.218 \\
\hline$R_{3}$ & $57.89 \%$ & 4 & 0.885 & & $57.89 \%$ & 4 & 0.885 \\
\hline$R_{4}$ & $55.01 \%$ & 5 & 0.635 & & $55.01 \%$ & 5 & 0.635 \\
\hline$O_{1}$ & $-47.76 \%$ & 6 & 0.435 & & $-47.76 \%$ & 6 & 0.435 \\
\hline $\mathrm{O}_{2}$ & $14.47 \%$ & 8 & 0.125 & & $14.47 \%$ & 8 & 0.125 \\
\hline $\mathrm{O}_{3}$ & $-47.36 \%$ & 7 & 0.268 & & $-47.36 \%$ & 7 & 0.268 \\
\hline $\mathrm{O}_{4}$ & $-71.76 \%$ & 1 & 2.718 & & $-71.76 \%$ & 1 & 2.718 \\
\hline \multicolumn{8}{|c|}{ Correlations } \\
\hline$\rho_{\bar{\imath}(B), \mathrm{npv}}$ & \multicolumn{3}{|l|}{1} & & & & \\
\hline$\rho_{S^{\bar{\imath}(B)}, S^{\mathrm{npv}}}$ & \multicolumn{3}{|l|}{1} & & & & \\
\hline
\end{tabular}

We now illustrate one numerical example where the DIM technique is used. It is a local SA technique, so it measures the value drivers' impact on the objective function in a neighbourhood of $\alpha^{0}$. We assume that changes in the inputs are proportional to the base value $\left(\mathrm{d} \alpha_{i}=\xi \cdot \alpha_{i}^{0}\right.$ for some $\left.\xi \neq 0\right)$ so the resulting DIM is

$$
\operatorname{DIM}_{i}^{f}\left(\alpha^{0}\right)=\frac{f_{\alpha_{i}}^{\prime}\left(\alpha^{0}\right) \cdot \xi \cdot \alpha_{i}^{0}}{\sum_{j=1}^{n} f_{\alpha_{j}}^{\prime}\left(\alpha^{0}\right) \cdot \xi \cdot \alpha_{j}^{0}}=\frac{f_{\alpha_{i}}^{\prime}\left(\alpha^{0}\right) \cdot \alpha_{i}^{0}}{\sum_{j=1}^{n} f_{\alpha_{j}}^{\prime}\left(\alpha^{0}\right) \cdot \alpha_{j}^{0}}
$$

(Borgonovo and Apostolakis 2001, Borgonovo and Peccati 2004). In particular, the first partial derivatives of $\operatorname{NPV}(\alpha)$, evaluated in $\alpha^{0}$, are

$$
\operatorname{NPV}_{\alpha_{i}}^{\prime}\left(\alpha^{0}\right)= \begin{cases}(1+k)^{-i}, & i=1,2,3,4 \\ -(1+k)^{-(i-4)}, & i=5,6,7,8\end{cases}
$$

The first partial derivatives of $\bar{\imath}(B)$, evaluated in $\alpha^{0}$, are

$$
\bar{\imath}(B)_{\alpha_{i}}^{\prime}\left(\alpha^{0}\right)=\operatorname{NPV}_{\alpha_{i}}^{\prime}\left(\alpha^{0}\right) \cdot \frac{1+k}{B} .
$$

Example 2. Consider a four-period investment $P$, with $B_{0}=900$ and $k=8 \%$. Hence, $\operatorname{Dep}_{t}=225$ which implies $B=2089.41$. The base value is

$$
\alpha^{0}=(900,1000,1100,1200,600,700,800,900) .
$$

The corresponding cash-flow vector is $\mathbf{F}=(-900,300,300,300,300)$ and NPV $=93.64$, 
$\bar{\imath}(B)=12.84 \%$. Table 4 shows the DIMs, the ranks, and the Savage scores. As expected, the two metrics share the same rank and even the same DIMs. Therefore, they are strictly coherent.

Table 4: Coherence under DIM technique

\begin{tabular}{|c|c|c|c|c|c|c|c|}
\hline \multirow[b]{2}{*}{ Parameter } & \multirow[b]{2}{*}{$\alpha^{0}$} & \multicolumn{3}{|c|}{ NPV } & \multicolumn{3}{|c|}{ Average ROI } \\
\hline & & $D I M_{i}^{\mathrm{npv}}\left(\alpha^{0}\right)$ & $r_{i}^{\mathrm{npv}}$ & $S_{i}^{\mathrm{npv}}$ & $D I M_{i}^{\bar{\imath}(B)}\left(\alpha^{0}\right)$ & $r_{i}^{\bar{\imath}(B)}$ & $S_{i}^{\bar{\imath}(B)}$ \\
\hline$R_{1}$ & 900 & $83.87 \%$ & 4 & 0.885 & $83.87 \%$ & 4 & 0.885 \\
\hline$R_{2}$ & 1000 & $86.28 \%$ & 3 & 1.218 & $86.28 \%$ & 3 & 1.218 \\
\hline$R_{3}$ & 1100 & $87.88 \%$ & 2 & 1.718 & $87.88 \%$ & 2 & 1.718 \\
\hline$R_{4}$ & 1200 & $88.77 \%$ & 1 & 2.718 & $88.77 \%$ & 1 & 2.718 \\
\hline$O_{1}$ & 600 & $-55.91 \%$ & 8 & 0.125 & $-55.91 \%$ & 8 & 0.125 \\
\hline $\mathrm{O}_{2}$ & 700 & $-60.40 \%$ & 7 & 0.268 & $-60.40 \%$ & 7 & 0.268 \\
\hline $\mathrm{O}_{3}$ & 800 & $-63.91 \%$ & 6 & 0.435 & $-63.91 \%$ & 6 & 0.435 \\
\hline $\mathrm{O}_{4}$ & 900 & $-66.58 \%$ & 5 & 0.635 & $-66.58 \%$ & 5 & 0.635 \\
\hline \multicolumn{8}{|c|}{ Correlations } \\
\hline$\rho_{\bar{\imath}(B), \mathrm{npv}}$ & 1 & & & & & & \\
\hline$\rho_{S^{\bar{\imath}(B)}, S^{\mathrm{npv}}}$ & 1 & & & & & & \\
\hline
\end{tabular}

\subsection{Declining-balance depreciation}

We discuss a model based on (2). In particular, we borrow from Hartman (2007, p. 344) a real-life application. In 2003, Sunoco Inc. agreed to build a coke-making plant with an annual capacity of 550,000 tons per year in order to supply plants of International Steel Group (ISG) Inc. The cost of the plant was $\$ 140$ million and ISG agreed to purchase the coke (needed for producing steel) for the next 15 years.

Table 5 collects the (stochastic and non-stochastic) relevant data affecting the project's economic profitability. The 11 stochastic parameters are evaluated in the base case $\alpha^{0}$. We assume that the facility is depreciated in 15 years with a double-declining balance switching to SL depreciation (DDB-SL), that is, $\operatorname{Dep}_{t}=\max \left(2 / p \cdot C_{t-1} ; C_{t-1} /(p-t+1)\right)$. This implies that the depreciation schedule is

$\mathbf{D e p}=(18.67,16.18,14.02,12.15,10.53,9.13,7.91,6.86,6.37,6.37,6.37,6.37,6.37,6.37,6.37)$.

From (2) the after-tax operating profit is obtained as

$$
I_{t}=\left(q \cdot p_{0}\left(1+g_{p}\right)^{t}-M\left(1+g_{m}\right)^{t}-L\left(1+g_{l}\right)^{t}-E\left(1+g_{e}\right)^{t}-O v-\mathrm{Dep}_{t}\right)(1-\tau) .
$$

Table 6 describes the value drivers at $\alpha^{0}$ and $\alpha^{1}$ and the resulting value of NPV and average ROI. The individual and total contribution of the value drivers, as well as the ranking, are measured via the First Order FCSI and the Total Order FCSI respectively (Tables 7 and 8). Unlike the previous example, the two FCSIs are not equal, owing to nonzero interactions among the value drivers. As expected, the effect of each parameter on average ROI is the same as its effect on NPV, in terms of both magnitude and direction, which means that the average ROI and the NPV are strictly coherent. ${ }^{8}$

${ }^{8}$ It is interesting to note that, while the change in both NPV and average ROI is not so large, the effect of 
Table 5: Sunoco project: Input data

\begin{tabular}{llll}
\hline \multicolumn{2}{l}{ Stochastic (value drivers) } & & \\
\hline Annual production & $q$ & 0.55 & million tons \\
Price & $p_{0}$ & $\$ 350$ & per ton \\
Price growth rate & $g_{p}$ & $2 \%$ & \\
Materials & $M$ & $\$ 27.5$ & million \\
Materials growth rate & $g_{m}$ & $2 \%$ & \\
Labor & $L$ & $\$ 75$ & million \\
Labor growth rate & $g_{l}$ & $5 \%$ & \\
Energy & $E$ & $\$ 20$ & million \\
Energy growth rate & $g_{e}$ & $3 \%$ & \\
Overhead & $O v$ & $\$ 7$ & million \\
Tax rate & $\tau$ & $35 \%$ & \\
\hline Non-stochastic & & & \\
\hline Investment & & $\$ 140$ & million \\
Salvage Value & & $\$ 0$ & million \\
COC & & $12 \%$ & \\
Periods & & 15 & years \\
Dep Method & & DDB-SL & \\
\hline
\end{tabular}

Table 6: Sunoco project evaluated in $\alpha^{0}$ and $\alpha^{1}$

\begin{tabular}{lrr}
\hline Parameter & $\alpha^{0}$ & $\alpha^{1}$ \\
\hline$q$ & 0.55 & 0.57 \\
$p_{0}$ & $\$ 350$ & $\$ 340$ \\
$g_{p}$ & $2.0 \%$ & $2.5 \%$ \\
$M$ & $\$ 27.5$ & $\$ 35.0$ \\
$g_{m}$ & $2.0 \%$ & $3.6 \%$ \\
$L$ & $\$ 75$ & $\$ 68$ \\
$g_{l}$ & $5.0 \%$ & $4.0 \%$ \\
$E$ & $\$ 20$ & $\$ 25$ \\
$g_{e}$ & $3.0 \%$ & $2.0 \%$ \\
$O$ & $\$ 7$ & $\$ 10$ \\
$\tau$ & $35.0 \%$ & $38.0 \%$ \\
\hline Valuation & $\alpha^{0}$ & $\alpha^{1}$ \\
\hline NPV & $\$ 120.61$ & $\$ 128.53$ \\
$\bar{\imath}(B)$ & $34.60 \%$ & $36.08 \%$ \\
\hline
\end{tabular}


Table 7: Sunoco project: First Order FCSI

\begin{tabular}{|c|c|c|c|c|c|c|}
\hline \multirow[b]{2}{*}{ Parameter } & \multicolumn{3}{|c|}{ NPV } & \multicolumn{3}{|c|}{ Average ROI } \\
\hline & $\Phi_{i}^{1, \mathrm{npv}}$ & $r_{i}^{\mathrm{npv}}$ & $S_{i}^{\mathrm{npv}}$ & $\Phi_{i}^{1, \bar{\imath}(B)}$ & $r_{i}^{\bar{\imath}(B)}$ & $S_{i}^{\bar{\imath}(B)}$ \\
\hline$q$ & $442.23 \%$ & 3 & 1.520 & $442.23 \%$ & 3 & 1.520 \\
\hline$p_{0}$ & $-347.47 \%$ & 6 & 0.737 & $-347.47 \%$ & 6 & 0.737 \\
\hline$g_{p}$ & $383.60 \%$ & 4 & 1.187 & $383.60 \%$ & 4 & 1.187 \\
\hline$M$ & $-473.82 \%$ & 2 & 2.020 & $-473.82 \%$ & 2 & 2.020 \\
\hline$g_{m}$ & $-183.24 \%$ & 8 & 0.427 & $-183.24 \%$ & 8 & 0.427 \\
\hline$L$ & $534.84 \%$ & 1 & 3.020 & $534.84 \%$ & 1 & 3.020 \\
\hline$g_{l}$ & $357.37 \%$ & 5 & 0.937 & $357.37 \%$ & 5 & 0.937 \\
\hline$E$ & $-336.21 \%$ & 7 & 0.570 & $-336.21 \%$ & 7 & 0.570 \\
\hline$g_{e}$ & $81.31 \%$ & 11 & 0.091 & $81.31 \%$ & 11 & 0.091 \\
\hline$O$ & $-167.82 \%$ & 9 & 0.302 & $-167.82 \%$ & 9 & 0.302 \\
\hline$\tau$ & $-107.70 \%$ & 10 & 0.191 & $-107.70 \%$ & 10 & 0.191 \\
\hline \multicolumn{7}{|c|}{ Correlations } \\
\hline$\rho_{\bar{\imath}(B), \mathrm{npv}}$ & 1 & & & & & \\
\hline$\rho_{S^{\bar{\imath}(B)}, S^{\mathrm{npv}}}$ & 1 & & & & & \\
\hline
\end{tabular}

Table 8: Sunoco project: Total Order FCSI

\begin{tabular}{|c|c|c|c|c|c|c|}
\hline \multirow[b]{2}{*}{ Parameter } & \multicolumn{3}{|c|}{ NPV } & \multicolumn{3}{|c|}{ Average ROI } \\
\hline & $\Phi_{i}^{T, \mathrm{npv}}$ & $r_{i}^{\mathrm{npv}}$ & $S_{i}^{\mathrm{npv}}$ & $\Phi_{i}^{T, \bar{l}(B)}$ & $r_{i}^{\bar{i}(B)}$ & $S_{i}^{\bar{\imath}(B)}$ \\
\hline$q$ & $422.70 \%$ & 3 & 1.520 & $422.70 \%$ & 3 & 1.520 \\
\hline$p_{0}$ & $-354.32 \%$ & 5 & 0.937 & $-354.32 \%$ & 5 & 0.937 \\
\hline$g_{p}$ & $368.36 \%$ & 4 & 1.187 & $368.36 \%$ & 4 & 1.187 \\
\hline$M$ & $-499.62 \%$ & 1 & 3.020 & $-499.62 \%$ & 1 & 3.020 \\
\hline$g_{m}$ & $-222.45 \%$ & 8 & 0.427 & $-222.45 \%$ & 8 & 0.427 \\
\hline$L$ & $478.34 \%$ & 2 & 2.020 & $478.34 \%$ & 2 & 2.020 \\
\hline$g_{l}$ & $309.06 \%$ & 6 & 0.737 & $309.06 \%$ & 6 & 0.737 \\
\hline$E$ & $-301.30 \%$ & 7 & 0.570 & $-301.30 \%$ & 7 & 0.570 \\
\hline$g_{e}$ & $96.95 \%$ & 11 & 0.091 & $96.95 \%$ & 11 & 0.091 \\
\hline$O$ & $-160.07 \%$ & 9 & 0.302 & $-160.07 \%$ & 9 & 0.302 \\
\hline$\tau$ & $-117.75 \%$ & 10 & 0.191 & $-117.75 \%$ & 10 & 0.191 \\
\hline \multicolumn{7}{|c|}{ Correlations } \\
\hline$\rho_{\bar{\imath}(B), \mathrm{npv}}$ & 1 & & & & & \\
\hline$\rho_{S^{\bar{\imath}(B)}, S^{\mathrm{npv}}}$ & 1 & & & & & \\
\hline
\end{tabular}


We now use Sunoco's example to show the behavior of the two metrics with the DIM technique. The computation of DIMs is easy, given that the calculation of the partial derivatives of NPV with respect to each parameter is straightforward (see Appendix B for the list of derivatives) and the derivatives of the average ROI is obtained from (25).

The strict coherence obviously holds. It is interesting to note that, in this case, there are ties: The first rank is shared by two key drivers, the current price, $p_{0}$, and the quantity sold, q. An equal relative change of either parameter affects the average ROI (and the NPV) in the same way. The operating costs related to labor are top drivers (labor cost has rank 3 and its growth rate has rank 4). Much less impact have the growth rates in energy and materials (rank 10 and 11, respectively).

Table 9: Sunoco project: DIM technique

\begin{tabular}{|c|c|c|c|c|c|c|c|}
\hline \multirow[b]{2}{*}{ Parameter } & \multirow[b]{2}{*}{$\alpha^{0}$} & \multicolumn{3}{|c|}{ NPV } & \multicolumn{3}{|c|}{ Average ROI } \\
\hline & & $D I M_{i}^{\mathrm{npv}}\left(\alpha^{0}\right)$ & $r_{i}^{\mathrm{npv}}$ & $S_{i}^{\text {npv }}$ & $D I M_{i}^{\bar{\imath}(B)}\left(\alpha^{0}\right)$ & $r_{i}^{\bar{\imath}(B)}$ & $S_{i}^{\bar{\imath}(B)}$ \\
\hline$q$ & 0.55 & $93.27 \%$ & 1.5 & 2.520 & $93.27 \%$ & 1.5 & 2.520 \\
\hline$p_{0}$ & 350 & $93.27 \%$ & 1.5 & 2.520 & $93.27 \%$ & 1.5 & 2.520 \\
\hline$g_{p}$ & $2 \%$ & $11.54 \%$ & 6 & 0.737 & $11.54 \%$ & 6 & 0.737 \\
\hline$M$ & 27.5 & $-13.32 \%$ & 5 & 0.937 & $-13.32 \%$ & 5 & 0.937 \\
\hline$g_{m}$ & $2 \%$ & $-1.65 \%$ & 11 & 0.091 & $-1.65 \%$ & 11 & 0.091 \\
\hline$L$ & 75 & $-43.95 \%$ & 3 & 1.520 & $-43.95 \%$ & 3 & 1.520 \\
\hline$g_{l}$ & $5 \%$ & $-14.26 \%$ & 4 & 1.187 & $-14.26 \%$ & 4 & 1.187 \\
\hline$E$ & 20 & $-10.31 \%$ & 7 & 0.570 & $-10.31 \%$ & 7 & 0.570 \\
\hline$g_{e}$ & $3 \%$ & $-1.95 \%$ & 10 & 0.191 & $-1.95 \%$ & 10 & 0.191 \\
\hline$O$ & 7 & $-3.00 \%$ & 9 & 0.302 & $-3.00 \%$ & 9 & 0.302 \\
\hline$\tau$ & $35 \%$ & $-9.64 \%$ & 8 & 0.427 & $-9.64 \%$ & 8 & 0.427 \\
\hline \multicolumn{8}{|c|}{ Correlations } \\
\hline$\rho_{\bar{\imath}(B), \mathrm{npv}}$ & 1 & & & & & & \\
\hline$\rho_{S^{\bar{\imath}(B)}, S^{\mathrm{npv}}}$ & 1 & & & & & & \\
\hline
\end{tabular}

\section{Concluding remarks}

Many different investment criteria are available to managers, professionals and practitioners. NPV is considered a theoretically reliable measure of economic profitability. Industrial and financial investments are often evaluated through relative measures of worth as well. Recently, it has been introduced a new class of return rates named AIRR (Magni 2010, Magni 2013). This class includes the average ROI, which plays an important role in the appraisal of industrial investments (Magni 2015, Mørch et al. 2017). The average ROI exists and is unique, and is coherent with NPV in the sense that it correctly signals value creation or value destruction, just like the NPV (and, therefore, the decision made using either metric is the same).

This work provides a new definition of NPV-consistency making use of sensitivity analysis (SA). Given an SA technique, a metric is strongly consistent or coherent with NPV if it fulfills the classical definition of NPV-consistency and generates the same ranking of the

each parameter on the two metrics is extremely high. In this model, the NPV and the average ROI are highly sensitive to the contributions of each driver but, overall, the parameters' effects reciprocally compensate, in such a way that the resulting change is "smoothed". 
value drivers as that generated by the NPV. If, in addition, the parameters' relevances are equal to the ones associated with NPV, then the metric and NPV are strongly consistent in a strict form.

We assume that the COC is exogenously fixed by the decision maker, as well as the initial investment and the lifetime of the project. After proving that an affine transformation of a function preserves the ranking, we show that the average ROI, being an affine transformation of NPV, is strongly NPV-consistent under several (possibly, all) different techniques of SA.

We have illustrated some simple numerical examples using FCSI (Borgonovo 2010a) and DIM (Borgonovo and Apostolakis 2001, Borgonovo and Peccati 2004), based on different depreciation plans (straight-line depreciation and accelerated depreciation). We have measured the degree of NPV-consistency via Spearman's (1904) coefficient and Iman and Conover's (1987) top-down coefficient. We have found that average ROI and NPV show perfect correlation and even strict consistency. However, we stress that not all AIRRs enjoy strong NPV-consistency, including the economic AIRR and the IRR, both showing degrees of incoherence that may be nonnegligible (see Appendix A).

The findings allow us to claim that the average ROI can be reliably associated with NPV, providing consistent pieces of information. Also, the average ROI is a good candidate for absolute NPV-consistency, to be intended as a strong coherence under any possible technique of SA (this should hold, given the affine relation between the average ROI and NPV). Future researches may be devoted to finding other relative measures of worth that enjoy strong NPV-consistency.

Acknowledgments. We thank four anonymous reviewers for their invaluable insights that have proved helpful in the revision of the paper.

\section{References}

Adelson, R.M. (1965) Criteria for capital investment: an approach through decision theory. Operational Research Quarterly 16, 19-50.

Ashford R.W., Berry, R.H., Dyson, R.G. (1988) Operational research and financial management. European Journal of Operational Research, 36, 143-152.

Baroum, S.M., Patterson, J.H. (1996) The development of cash flow weight procedures for maximizing the net present value of a project. Journal of Operations Management, 14(3) (September), 209-227.

Barry, P.J., Robison, L.J. (2014) Technical note: Economic rates of return and investment analysis. The Engineering Economist, 59(3), 231-236.

Ben-Horin, M., Kroll, Y. (2017) A simple intuitive NPV-IRR consistent ranking. The 
Quarterly Review of Economics and Finance. < https://doi.org/10.1016/j.qref.2017.01.004>.

Baesens B., Setiono R., Mues C., Vanthienen, J. (2003) Using neural network rule extraction and decision tables for credit-risk evaluation. Management Science 49, 312329.

Bernhard, R.H. (1980) A simplification and an extension of the Bernhard-De Faro sufficient condition for a unique non-negative internal rate of return. Journal of Financial and Quantitative Analysis. 15(1), 201-209.

Board, J., Sutcliffe, C., Ziemba, W.T. (2003) Applying operations research techniques to financial markets. Interfaces, 33(2) (Mar-Apr), 12-24.

Borgonovo, E. (2010a) Sensitivity analysis with finite changes: An application to modified EOQ models. European Journal of Operational Research, 200, 127-138.

Borgonovo, E. (2010b) A Methodology for Determining Interactions in Probabilistic Safety Assessment Models by Varying One Parameter at a Time. Risk Analysis, 30 (3), 385-399.

Borgonovo, E., Apostolakis, G. E. (2001) A new importance measure for risk-informed decision-making. Reliability Engineering and System Safety, 72 (2), 193-212.

Borgonovo, E., Gatti, S., Peccati, L. (2010) What drives value creation in investment projects? An application of sensitivity analysis to project finance transactions. European Journal of Operational Research, 205, 227-236.

Borgonovo, E., Peccati, L. (2004) Sensitivity analysis in investment project evaluation. International Journal of Production Economics, 90, 17-25.

Borgonovo, E., Peccati, L. (2006a) The importance of assumptions in investment evaluation. International Journal of Production Economics, 101(2) (June), 298-311.

Borgonovo, E., Peccati, L. (2006b) Uncertainty and global sensitivity analysis in the evaluation of investment projects. International Journal of Production Economics, 104, 62-73.

Borgonovo, E., Plischke, E. (2016) Sensitivity analysis: A review of recent advances. European Journal of Operational Research, 248(3), 869-887.

Borgonovo, E., Tarantola, S., Plischke, E., Morris, M.D. (2014) Transformations and invariance in the sensitivity analysis of computer experiments. Journal of the Royal Statistical Society, B, 76, Part 5, 925-947.

Bosch-Badia, M.T., Montllor-Serrats, J., Tarrazon-Rodon, M.A. (2014) Capital budgeting and shareholders value: Investment projects versus courses of action. The Engineering Economist, 59, 207-230. 
Brealey, R.A., Myers, S.C. (2000) Principles of Corporate Finance. McGraw-Hill, New York.

Brimberg, J., Hansen, P., Laporte, G., Mladenovic, N., Urosevic, D. (2008) The maximum return-on-investment plant location problem with market share. Journal of the Operational Research Society, 59(3), 399-406.

Brimberg, J., ReVelle, C. (2000) The maximum return-on-investment plant location problem. Journal of the Operational Research Society, 51(6) (June), 729-735.

Bring, J. (1994) How to standardize regression coefficients. The American Statistician, 48(3)(August), 209-213.

Cigola, M., Peccati, L. (2005) On the comparison between the APV and the NPV computed via the WACC. European Journal of Operational Research, 161(2) (March), 377-385.

Danaher, P.J., Rust, R.T. (1996) Determining the optimal return on investment for an advertising campaign. European Journal of Operational Research, 95(3) (December), 511521.

Dhavale, D.G., Sarkis, J. (2018) Stochastic internal rate of return on investments in sustainable assets generating carbon credits. Computers \& Operations Research, 89 (January), 324-336.

De Faro, C. (1978) A sufficient condition for a unique non-negative internal rate of return: Further comment. Journal of Financial Quantitative Analysis, 13, 577-584.

Ekern, S. (1981) Time Dominance Efficiency Analysis. Journal of Finance, 36(5) (December), 1023-1034.

Fabozzi, F.J., Huang, D., Zhou, G. (2010) Robust portfolios: contributions from operations research and finance. Annals of Operations Research, 176(1) (April), 191-220.

Foster, J.E., Mitra, T. (2003) Ranking investment projects. Economic Theory, 22, 469494 .

Gondzio, J., Kouwenberg, R. (2001) High-performance computing for asset-liability management. Operations Research, 49(6) (November-December), 879-891.

Grubbström, R.W., Ashcroft, S.H. (1991) Application of the calculus of variations to financing alternatives. Omega, 19(4), 305-316.

Hartman, J.C. and Schafrick, I.C. (2004) The relevant internal rate of return. The Engineering Economist, 49(2). 
Hartman, J. (2007) Engineering economy and the decision-making process. Pearson Prentice Hall, Upper Saddle River, NJ.

Hazen, G.B. (2003) A new perspective on multiple internal rates of return. The Engineering Economist, 48(1), 31-51.

Hazen, G.B. (2009) An extension of the internal rate of return to stochastic cash flows. Management Science, 55, 1030-1034.

Helton, J.C. (1993) Uncertainty and sensitivity analysis techniques for use in performance assessment for radioactive waste disposal. Reliability Engineering and System Safety, 42, 327-367.

Herroelen, W.S., Van Dommelen, P., Demeulemeester, E.L. (1997) Project network models with discounted cash flows a guided tour through recent developments. European Journal of Operational Research, 100(1) (July), 97-121.

Hespos, R.F., Strassman, P.A. (1965) Stochastic decision trees for the analysis of investment decisions. Management Science, 11(19) (August), 224-259.

Ignizio, J.P. (1976) An approach to the capital budgeting problem with multiple objectives. The Engineering Economist, 21(4), 259-272.

Iman, R.L., Conover, W.J. (1987) A measure of top-down correlation. Technometrics, 29 (3), 351-357.

Joy, O.M., Bradley, J.O. (1973) A note on sensitivity analysis of rates of return. Journal of Finance (December 1973), 1255-1261.

Koç, A., Morton, D.P., Popova, E. Hess, S.M., Kee, E., Richards, D. (2009) Prioritizing project selection. The Engineering Economist, 54(4), 267-297.

Kumbhakar, S.C. (2011) Estimation of production technology when the objective is to maximize return to the outlay. European Journal of Operational Research, 208(2) (January), 170-176.

Leyman, P., Vanhoucke, M. (2017) Capital- and resource-constrained project scheduling with net present value optimization. European Journal of Operational Research, 256(3) (February), 757-776.

Li, J., Min, K.J., Otake, T., Van Voorhis, T. (2008) Inventory and investment in setup and quality operations under Return On Investment maximization. European Journal of Operational Research, 185(2) (March), 593-605.

Lima e Silva, J., Sobreiro, V.A., Kimura, H. (2017) Pre-Purchasing financing pool: Reveal- 
ing the IRR problem. The Engineering Economist, DOI: 10.1080/0013791X.2017.1333662.

Magni, C.A. (2010) Average Internal Rate of Return and investment decisions: A new perspective. The Engineering Economist, 55(2), 150-180.

Magni, C.A. (2013) The Internal Rate of Return approach and the AIRR Paradigm: A refutation and a corroboration. The Engineering Economist: A Journal Devoted to the Problems of Capital Investment, 58(2), 73-111.

Magni, C.A. (2014) Mathematical analysis of average rates of return and investment decisions: The missing link. The Engineering Economist, 59(3), 175-206.

Magni, C.A. (2015) Investment, financing and the role of ROA and WACC in value creation. European Journal of Operational Research, 244, 855-866.

Magni, C.A. (2016) Capital depreciation and the underdetermination of rate of return: A unifying perspective. Journal of Mathematical Economics, 67 (December), 54-79.

Menezes, M.B.C., Kim, S., Huang, R. (2015) Return-on-investment (ROI) criteria for network design. European Journal of Operational Research, 245(1) (August), 100-108.

Meier, H., Christofides, N., Salkin, G. (2001) Capital Budgeting Under UncertaintyAn Integrated Approach Using Contingent Claims Analysis and Integer Programming. Operations Research, 49(2) (March-April), 196-206.

Mørch, O., Fagerholta, K., Pantuso, G., Rakkec, J. (2017) Maximizing the rate of return on the capital employed in shipping capacity renewal. Omega, 67 (March), 42-53.

Murthi, B.P.S., Choi, Y.K., Desai, P. (1997) Efficiency of mutual funds and portfolio performance measurement: A non-parametric approach. European Journal of Operational Research, 98(2) (April), 408-418.

Myung, Y.-S., Kim, H., Tcha, D. (1997) A bi-objective uncapacitated facility location problem. European Journal of Operational Research, 100(3), 608-616.

Nauss, R.M. (1988) On the use of internal rate of return in linear and integer programming. Operations Research Letters, 7(6) (December), 285-289.

Pasqual, J., Padilla, E., Jadotte, E. (2013) Technical note: Equivalence of different profitability criteria with the net present value. International Journal of Production Economics, 142(1) (March), 205-210.

Percoco, M., Borgonovo, E. (2012) A note on the sensitivity analysis of the internal rate of return. International Journal of Production Economics, 135, 526-529. 
Pianosi, F., Beven, K., Freer, J., Hall, J.W., Rougier, J., Stephenson, D.B., Wagener, T. (2016) Sensitivity analysis of environmental models: A systematic review with practical workflow. Environmental Modelling \& Software, 79, 214-232.

Rapp, B. (1980) The Internal Rate of Return method - A critical study. Engineering Costs and Production Economics, 5(1) (June), 43-52.

Rivett, P. (1974) Perspective for Operational Research. Omega, 2(2), 225-233.

Rosenblatt, M.J., Sinuany-Stern, Z. (1989) Generating the discrete efficient frontier to the capital budgeting problem. Operations Research, 37(3), 384-394.

Ross, S.A., Westerfield, R.W., Jordan, B.D. (2011) Essentials of corporate finance, 7th ed. McGraw-Hill/Irwin, New York.

Saltelli, A., Marivoet, J. (1990) Non-parametric statistics in sensitivity analysis for model output: A comparison of selected techniques. Reliability Engineering and System Safety, $28,229-253$.

Saltelli, A., Ratto, M., Andres, T., Campolongo, F., Cariboni, J., Gatelli, D., Saisana, M., Tarantola, S. (2008) Global Sensitivity Analysis. The Primer. John Wiley \& Sons, Chichester.

Saltelli, A., Tarantola, S., Campolongo, F., Ratto, M. (2004) Sensitivity analysis in practice. A guide to assessing scientific models. John Wiley \& Sons, Chichester.

Savage, I.R. (1956) Contributions to the theory of rank order statistics - The two-sample case. The Annals of Mathematical Statistics, 27(3), 590-615.

Seifert, D., Seifert, R.W., Protopappa-Siekec, M. (2013) A review of trade credit literature: Opportunities for research in operations. European Journal of Operational Research, 231(2) (December), 245-256.

Small, P.H. (1956) Operations Research from a financial viewpoint. Operations Research, $4,581-587$.

Sobol', I.M. (1993) Sensitivity estimates for nonlinear mathematical models. Mathematical Modeling and Computational Experiments, 1(4), 407-414.

Sobol', I.M. (2001) Global sensitivity indices for nonlinear mathematical models and their Monte Carlo estimates. Mathematics and Computers in Simulation, 55, 271-280.

Soper, C.S. (1959) The marginal efficiency of capital: A further note. The Economic Journal, 69 (March), 174-177. 
Spearman, C. (1904) The proof and measurement of association between two things. The American Journal of Psychology, 15(1), 72-101.

Spronk, J, Hallerbach, W. (1997) Financial modelling: Where to go? With an illustration for portfolio management. European Journal of Operational Research, 99(1) (May), 113125.

Steuer, R.E., Na, P. (2003) Multiple criteria decision making combined with finance: A categorized bibliographic study. European Journal of Operational Research, 150(3) (November), 496-515.

Talavera, D.L., Nofuentes, G., Aguilera, J. (2010) The internal rate of return of photovoltaic grid-connected systems: A comprehensive sensitivity analysis. Renewable Energy, 35(1) (January), 101-111.

Teichroew, D., Robichek, A., Montalbano, M. (1965a) Mathematical analysis of rates of return under certainty. Management Science, 11, 395-403.

Teichroew, D., Robichek, A., Montalbano, M. (1965b) An analysis of criteria for investment and financing decisions under certainty. Management Science, 12, 151-179.

Thomas L.C. (2010) Consumer finance: challenges for operational research. Journal of the Operational Research Society, 61(1) (January), 41-52.

Weingartner, H.M. (1963) Mathematical Programming and the Analysis of Capital Budgeting Problems, Prentice-Hall, Englewood Cliffs, NJ.

White, G.I., Sondhi, A.C., Fried, D. (1997) The Analysis and Use of Financial Statements. Second edition. Wiley, New York, USA.

Wiesemann, W., Kuhn, D., Rustem, B. (2010) Maximizing the net present value of a project under uncertainty. European Journal of Operational Research, 202(2) (April), 356-367.

Xu, X., Birge, J.R (2008) Operational decisions, capital structure, and managerial compensation: A news vendor perspective. The Enginering Economist, 53(3), 173-196.

Yang, K.K., Talbot, F.B., Patterson, J.H. (1993) Scheduling a project to maximize its net present value: An integer programming approach. European Journal of Operational Research, 64(2) (January), 188-198.

\section{Appendix A. (Non)strong consistency of other AIRRs}

In principle, the class of AIRRs consists of infinitely many rates of return (albeit most of them non-economically significant), so it is no wonder that many of them are not strongly- 
consistent. In this appendix we briefly focus on four special cases of AIRR, three of which are not strongly consistent with NPV.

Internal rate of return (IRR). Magni $(2010,2013)$ shows that the internal rate of return (IRR) is a special case of AIRR. Specifically, the IRR is a weighted mean of generally time-varying period rates, generated by any vector $\mathbf{C}$ fulfilling the following condition: $C=\sum_{t=1}^{p} \sum_{k=t}^{p} F_{k}(1+x)^{-(p-t+1)} \cdot(1+k)^{-(t-1)} \cdot{ }^{9}$ While the IRR is traditionally NPV-consistent (Hazen 2003), it suffers from some difficulties that have been extensively investigated in the literature. A part of it has been concerned with the necessary and sufficient condition for existence and uniqueness (e.g., Soper 1959, De Faro 1978, Bernhard 1980. See also Magni 2010 and references therein) or with project ranking (see Ekern 1981, Foster and Mitra 2003 for ranking of risk-free projects. See Ben-Horin and Kroll 2017 for ranking of nonequivalent-risk projects). In particular, Ekern (1981) and Foster and Mitra (2003) can be interpreted as supplying conditions of (non)existence of IRR in the interval $(0,+\infty)$, assuming that a project is ranked against the null alternative. Therefore, they provide a tool to measure the robustness of a value-creating project under changes in the COC and, at the same time, the conditions where IRR does not exist and cannot then be employed for ranking value drivers. ${ }^{10}$ Percoco and Borgonovo (2012) show that, if the IRR exists and is unique, the ranking of value drivers provided by IRR is not equal to the ranking provided by the NPV, which means that the IRR is not strongly NPV-consistent. It is easy to see that its degree of NPV-inconsistency, as measured by Spearman's correlation coefficient or Iman and Conover's top-down coefficient, may be not negligible. ${ }^{11}$ Also, the financial nature of the IRR is not unambiguously determined: An investment project may well turn to a financing project if value drivers change, which makes SA meaningless.

Economic AIRR (EAIRR). Another relevant AIRR is the economic AIRR, based on market values (Magni 2013, 2014, Barry and Robison 2014, Bosch-Badia et al. 2014). It is generated by picking $C_{t}=\sum_{k=t+1}^{p} F_{k}(1+k)^{t-k}$ for all $t=1, \ldots, p-1$ (while $C_{0}=-F_{0}$ ), which represents the economic value of the project at time $t$. The EAIRR is NPV-consistent in a traditional sense and, unlike the IRR, this AIRR always exists and is unique. However, just like the IRR, its financial nature may change under changes in the value drivers.

Strong consistency with NPV is not guaranteed because $C_{t}$ (and, therefore, $C$ ) depends on $\mathbf{F}$ which, in turn, depends on the value drivers. Hence, it is not an affine transformation of NPV. The degree of inconsistency may be rather high. ${ }^{12}$

\footnotetext{
${ }^{9}$ This implies that the assumption $i_{t}=x$ for all $t$ is sufficient but not necessary to generate a rate of return equal to IRR.

${ }^{10} \mathrm{It}$ is usually believed that the case of no-IRR is very rare. However, in some engineering projects it is not infrequent that disposal and remedial costs occur at the terminal date, which is a necessary condition for inexistence of IRR. Most recently, Lima e Silva et al. (2017) focus on a very common transaction where the case of (multiple IRRs and) no IRR is the rule rather than the exception.

${ }^{11}$ For instance, in Example 1, the ranking generated by IRR with Total Order FCSIs is $(1,2,4,6,3,8,7,5)$ and the top-down coefficient is $\rho_{S^{\mathrm{npv}}, S^{\text {irr }}}=0.409$. In Example 2, where the DIM technique is used, the parameters ranking supplied by IRR is $(1,2,3,4,8,7,5,6)$ and the top-down coefficient is $\rho_{S^{\mathrm{npv}}, S^{\mathrm{irr}}}=0.309$.

${ }^{12}$ In Example 1, the Total Order FCSIs for EAIRR generate the parameters' ranking $(1,2,4,6,3,8,5,7)$ and $\rho_{S^{\text {npv }}, S^{\text {eairr }}}=0.239$. In Example 2 the ranking is $(1,2,3,4,8,7,5,6)$ (equal to the ranking of IRR) and, therefore, the top-down coefficient is equal as well: $\rho_{S^{\text {npv }}, S^{\text {eairr }}}=0.309$.
} 
Modified internal rate of return (MIRR). The MIRR approach, also known as the external-rate-of-return approach, consists of modifying project $P$ by discounting and/or compounding some or all of its cash flows at an external rate so as to generate a modified project $P^{\prime}$ (with a modified cash-flow stream $\mathbf{F}^{\prime}$ ) bearing the same NPV as $P$ but such that $\mathbf{F}^{\prime}$ has only one change in sign for the cash-flow stream. This guarantees that the IRR of $P^{\prime}$ (i.e., the MIRR of $P$ ) exists and is unique. The MIRR suffers from some ambiguities of definition: (i) it is not clear what the external rate should be, (ii) there are many ways to modify the project (resulting in different MIRRs), none of which seems to deserve a privileged status, and (iii) it does not actually measure $P$ 's rate of return (see Brealey and Myers 2000, Ross et al. 2011, Magni 2015).

Being an IRR of $P^{\prime}$, the MIRR is an AIRR of $P^{\prime}$ and is not strongly consistent. Further, the external rate from which it depends adds a source of uncertainty in the valuation process (it may be equal or different from the COC). This implies that the MIRR may not be NPV-consistent, not even in the traditional sense (see Magni 2015, Appendix).

Profitability Index (PI). PI is defined as $P I=\mathrm{NPV} / B_{0}$. It is a well-known and widespread metric that measures the NPV per unit of initial investment. It is strongly consistent with NPV in a strict sense, as it is an affine transformation of NPV. It is also easily seen that the PI is strictly linked with AIRR; namely, if cash-flow accounting is used, that is, assets are expensed immediately (whence $B_{t}=0$ for $t>0$ ), then $B=B_{0}$ and, from $(9), \bar{\imath}\left(B_{0}\right)=k+\operatorname{NPV}(1+k) / B_{0}$ whence $P I=\left(\bar{\imath}\left(B_{0}\right)-k\right) /(1+k)$. Therefore, PI is an affine transformation of the average ROI that is associated with a cash-flow-accounting depreciation system. 


\section{Appendix B. Partial derivatives}

$$
\begin{aligned}
& \operatorname{NPV}_{q}^{\prime}\left(\alpha^{0}\right)=p_{0} \cdot(1-\tau) \cdot \sum_{t=1}^{15}\left(\frac{1+g_{p}}{1+k}\right)^{t}, \\
& \mathrm{NPV}_{p_{0}}^{\prime}\left(\alpha^{0}\right)=q \cdot(1-\tau) \cdot \sum_{t=1}^{15}\left(\frac{1+g_{p}}{1+k}\right)^{t}, \\
& \mathrm{NPV}_{g_{p}}^{\prime}\left(\alpha^{0}\right)=p_{0} \cdot q \cdot(1-\tau) \cdot \sum_{t=1}^{15} \frac{t \cdot\left(1+g_{p}\right)^{t-1}}{(1+k)^{t}}, \\
& \mathrm{NPV}_{M}^{\prime}\left(\alpha^{0}\right)=-(1-\tau) \cdot \sum_{t=1}^{15}\left(\frac{1+g_{m}}{1+k}\right)^{t}, \\
& \mathrm{NPV}_{g_{m}}^{\prime}\left(\alpha^{0}\right)=-M \cdot(1-\tau) \cdot \sum_{t=1}^{15} \frac{t \cdot\left(1+g_{m}\right)^{t-1}}{(1+k)^{t}}, \\
& \mathrm{NPV}_{L}^{\prime}\left(\alpha^{0}\right)=-(1-\tau) \cdot \sum_{t=1}^{15}\left(\frac{1+g_{l}}{1+k}\right)^{t}, \\
& \mathrm{NPV}_{g_{l}}^{\prime}\left(\alpha^{0}\right)=-L \cdot(1-\tau) \cdot \sum_{t=1}^{15} \frac{t \cdot\left(1+g_{l}\right)^{t-1}}{(1+k)^{t}}, \\
& \operatorname{NPV}_{E}^{\prime}\left(\alpha^{0}\right)=-(1-\tau) \cdot \sum_{t=1}^{15}\left(\frac{1+g_{e}}{1+k}\right)^{t}, \\
& \operatorname{NPV}_{g_{e}}^{\prime}\left(\alpha^{0}\right)=-E \cdot(1-\tau) \cdot \sum_{t=1}^{15} \frac{t \cdot\left(1+g_{e}\right)^{t-1}}{(1+k)^{t}}, \\
& \operatorname{NPV}_{O}^{\prime}\left(\alpha^{0}\right)=-(1-\tau) \cdot \sum_{t=1}^{15} \frac{1}{(1+k)^{t}}, \\
& \operatorname{NPV}_{\tau}^{\prime}\left(\alpha^{0}\right)=-\sum_{t=1}^{15} \frac{I_{t}}{(1-\tau) \cdot(1+k)^{t}} \cdot
\end{aligned}
$$

